Utah State University

DigitalCommons@USU

5-1972

\title{
Evaluation of the Filter Paper Method for Estimating Soil Water Potential
}

Samir Al-Khafaf

Utah State University

Follow this and additional works at: https://digitalcommons.usu.edu/etd

Part of the Soil Science Commons

\section{Recommended Citation}

Al-Khafaf, Samir, "Evaluation of the Filter Paper Method for Estimating Soil Water Potential" (1972). All

Graduate Theses and Dissertations. 3000.

https://digitalcommons.usu.edu/etd/3000

This Thesis is brought to you for free and open access by the Graduate Studies at DigitalCommons@USU. It has been accepted for inclusion in All Graduate Theses and Dissertations by an authorized administrator of DigitalCommons@USU. For more information, please contact digitalcommons@usu.edu.

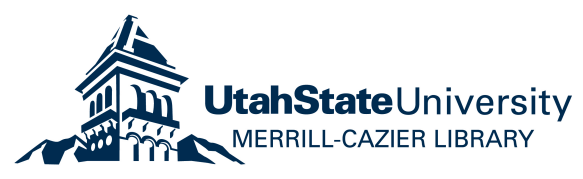


EVALUATION OF THE FILTER PAPER METHOD

FOR ESTIMATING SOIL WATER POTENTIAL

by

Samir A1-Khafaf

A thesis submitted in partial fulfillment of the requirements for the degree

of

MASTER OF SCIENCE

in

Department of Soil Science and Biometeorology

in

Soil Physics

Approved :

UTAH STATE UNIVERSITY

Logan, Ut ah 


\section{ACKNOWLEDGMENTS}

I am grateful and indebted to Dr. R. J. Hanks, who supervised the research, for his assistance, continuous encouragement, deep interest, valuable advice, guidance throughout this work, and finally his active interest in providing all the necessary equipment for this work.

Sincere gratitude is also extended to Dr. A. Southard and Dr. L. King, committee members, for their advice and suggestions to improve this thesis; and to Musa Nimah, graduate student of soil physics, for his valuable help in clearing up many points in the development of this work. Grateful appreciation is expressed to the Iraqi Government, Ministry of Higher Education and Research, Mosul University, for support of my studies at Utah State University, and especially to my college, Agriculture and Forestry, for their concern and constant encouragement; and to Mrs. Betty Smith for editorial assistance and typing.

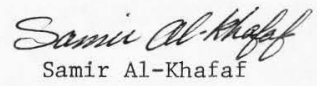


Objectives

REVIEW OF LITERATURE

Other Methods of Measuring Water Potential .

Tensiometer

Pressure membrane

Electrical resistance units

Thermocouple psychrometer

Theory

MATERIALS AND METHODS

Appratus and supplies

Soil samples

Mesa sandy loam

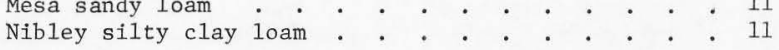

PROCEDURE

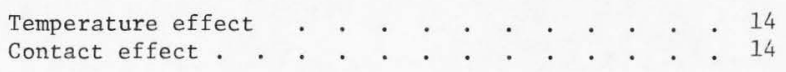

RESULTS AND DISCUSSION . . . . . . . . . . . . . . . 16

Temperature effect . . . . . . . . . . . . 18

Uncertain contact . . . . . . . . . . . . 22

Good contact . . . . . . . . . . . 24

No contact . . . . . . . . . . . . . . . 27

SUMMARY AND CONCLUSIONS • • . . . . . . . . . . . . . . 32

REFERENCES . . . . . . . . . . . . . . . . . . . 33

APPENDIX . . . . . . . . . . . . . . . . . . . 36

VITA . . . . . . . . . . . . . . . . . . . . . 52 
1. Particle size distribution of Nibley clay loam and Mesa sandy loam

2. Effect of type of equilibrium environment, water content, sample size and water content at time of equilibration on the water content (by weight) of the filter paper. Mesa sandy loam. Filter paper not in contact with soil . . . 16

3. Same as Table 2 except filter paper in contact with soil . 17

4. Influence of type of equilibrium environment on the filter paper water content $(\theta)$ as a function of sample size and soil water content. Filter paper taped to lids of cans not in contact with soil

5. Calibration data from samples wetted to certain water content in a constant temperature chamber. $\psi$ was measured with the thermocouple psychrometer. Temperature of calibration was $15 \pm 0.1^{\circ} \mathrm{C} . \mathrm{T}=$ uncertain contact. $\mathrm{B}=$ good contact

6. Same as Table 5 except temperature of calibration was 20 $\pm .1^{\circ} \mathrm{C}$

7. Same as Table 5 except temperature of calibration was 24 $\pm .1^{\circ} \mathrm{C}$

8. Same as Table 5 except temperature of calibration without control

9. Same as Table 5 except temperature of calibration was $32^{\circ} \mathrm{C} .45$

10. Data were collected from soil samples obtained at known heights above the water table, the filter papers were equilibrated the same as in Table 5. . . . . . . . . 47

11. Same as Table 5 except temperature of calibration was $24 \pm .1^{\circ} \mathrm{C}$ and the filter paper separated from the soil by a cylinder. . . . . . . . . . . . . 48

12. Calibration data of the filter paper exposed to saturated salts in constant temperature chamber . . . . . . . 50

13. Same as Table 5 except temperature of calibration was $20 \pm 1{ }^{\circ} \mathrm{C}$ and $\psi$ was measured using the pressure plate membrane 


\section{LIST OF FIGURES}

Figure

Page

1. Diagram of equipment used to measure soil water potential. Also shows types of contact between filter paper and soil samples . . . . . . . . . . . 10

2. Calibration data showing influence of temperature treatments used in this study. $\psi$ was measured with the thermocouple psychrometer . . . . . . . 20

3. Calibration data showing influence of the temperature treatments used in this study. $\psi$ was measured by thermocouple psychrometers . . . . . . . . . . 21

4. Summary of all data in Figure 2, pooled and plotted as one treatment. Also shown is the comparison between data of this method and the method used by McQueen and Miller

5. Summary of all data in Figure 3 pooled and plotted as one treatment. Also shown is the comparison between this method and the method used by McQueen and Miller . . . 25

6. Summary of all data for good contact (1ow, medium and high water potential). Also shown is the comparison between this method and method used by McQueen and Miller . 26

7. Summary of all data for uncertain contact (low, medium and high water potential). Also shows comparison between this method and method used by McQueen and Miller . . . 28

8. Summary of data (good contact) showing comparison among the methods used in this study, the McQueen and Miller and the Gardner method

9. Summary of calibration data showing comparison between two methods used in this study (no contact, salt solution for calibration) and method used by McQueen and Miller . 30 


\author{
ABSTRACT \\ Evaluation of the Filter Paper Method \\ For Estimating Soil Water Potential \\ by \\ Samir A1-Khafaf, Master of Science \\ Utah State University, 1972
}

Major Professor: Ronald J. Hanks

Department: Soil Science and Biometeorology

The filter paper method for measuring soil water potential was evaluated. The method was calibrated using salt solutions $(-1.4$ bars to -22.4 bars), sample chamber psychrometer ( -1 to -50 bars), pressure plate ( -0.1 to -15 bars) and soil column at equilibrium ( 0 to -0.2 bars). It was found that the absolute temperature had little effect on the predicted soil water potential, but a temperature variation had a large effect. It was found that the temperature fluctuation must be small. The predicted water potential was influenced by the type of contact of the soil with the filter paper. It is suggested that one filter paper be placed beneath the soil (good contact for liquid or vapour flow) and one filter paper be placed above the soil not in physical contact (allowing vapour flow only).

The equilibrium between the filter paper and soil mass was essentially completed by the end of two days and certainly by the end of five days. 
INTRODUCTION

A knowledge of soil water content is not sufficient to describe the water status of a soil. It is common experience that different soils have different water contents when treated in similar ways. Plants do not grow equally well on different soils that have the same water content. A soil property, called the soil water potential, has been defined that is directly related to the ease with which plants extract water. The soil water potential is also needed to describe soil water flow. Measurement of the soil water potential has received major attention from those who are concerned with water relations of plants and soils. It has also received attention from soil physicists and engineers. To evaluate the condition of water in the soil, it would be desirable to know both the water content and water potential in space and time (Taylor, Evans and Kemper, 1961). Since plants respond much more closely to the water potential than to water content of a soil (Stanhill, 1957), it is often more desirable to know the water potential than the amount of water in the soil.

The standard methods for measuring the water potential are limited because they do not cover the range of potential values expected on arid lands and/or they do not adapt to use on field samples. The filter paper method of evaluating the soil water potential has been claimed to overcome some of these limitations (McOueen and Miller, 1968; and Gardner, 1937). 
The filter paper method is based on the assumption that the water potential of moist soil and filter paper in contact with the soil will be the same at equilibrium. The method further assumes that if the soil sample is large compared to the filter paper, the water potential of the soil will be essentially the same before and after it is placed in contact with the filter paper. Since filter paper can be obtained with highly uniform quality, it should be possible to estimate the water potential of a soil from the measurement of the water content of the filter paper in equilibrium with the soil. If the filter paper is properly calibrated and always wet, to avoid hysteresis, a relatively simple method should result.

This principle of the method is undoubtedly sound, providing a good system can be devised where the water potential during equilibration does not change and the effect of temperature can be eliminated. The method also has the problem associated with uncertainties due to contact and whether equilibrium is with water vapor or liquid.

Preliminary evaluation of the method, however, indicated several problems with contact, temperature of equilibration, and temperature variation during equilibrium. Consequently, it was decided to make a thorough study of the method and factors influencing its results.

\section{Objectives}

The general objective of the study was to test the filter paper method of estimating soil water potential over a wide range of soil mo isture.

The specific objectives were to evaluate the influence of type of contact, temperature and temperature variation on the relation of filter paper water content to soil water potential. 


\section{REVIEW OF LITERATURE}

The total water potential (or energy per unit quantity) of water, $\psi$, is defined as the mechanical work required to transfer a unit quantity (e.g., unit mass, unit weight or unit volume) of water from a standard reference state, where $\psi$ is taken as zero, to the location where the potential has the defined value (Rose, 1966).

It is convenient to divide the total potential into four component potentials :

1. Gravity potential, which relates to position in the gravitational field with respect to an arbitrary reference elevation.

2. Matric potential, which relates to adsorption forces between solid surfaces and water, including the effect of cohesive forces between water molecules.

3. Osmotic potential, which relates to forces of attraction between ions and water molecules.

4. Pneumatic potential, which relates to forces arising from unequal pressure in the gaseous phase (Boersma et al., 1970).

The filter paper method may measure the sum of the matric and osmotic potentials if there is only vapor flow during equilibration or may measure only the matric potential if there is liquid flow during equilibration. Thus, the type of contact is important. The gravitational potential is not dependent on soil properties but depends only on the vertical distances between the references and the point in question. For most field situations the pneumatic potential is zero. 
The use of paper as a water potential sensor has gradually evolved in Europe and the United States. Hansen (1926) working at the University of Copenhagen used blotting paper as a carrier for sugar solutions. The method, which he used for measuring the water potential of the soil, involved determining the osmotic potential of the sugar solution which had the same vapour pressure as the soil sample under investigation. Blotting paper strips, saturated with four different concentrations of sugar solutions of a previously determined osmotic potential were weighed and then exposed to soil samples in closed chambers. After 24 hours the filter paper was again weighed. The sugar solution that did not lose or gain weight was assumed to represent the water potential in the sample. Stocker (1930) used a similar procedure with a larger number of sugar solution concentrations for better accuracy. Gardmann (1934) improved the method by using a single strip of blotting paper soaked in salt solution and then calibrated for weight versus potential. The first use of filter paper to determine the water potential of the soil in the United States was reported by Gardner (1937). Enough soil to fill a $10 \mathrm{~cm}$ petri dish was made up to approximately the desired moisture content. One-third of this was placed in a smooth layer in the dish and covered with a dry $9 \mathrm{~cm}$ diameter filter paper. This was covered with another one-third of the soil. A wet filter paper was placed on this layer and covered with the rest of the soil. The cover was then placed on the dish and the dish stored for 5 or 6 days in a closed vessel at approximately $25^{\circ} \mathrm{C}$. At the end of this period, the papers were removed from the dishes and the water content of the filter paper and soil sample were measured. For the low water potentials (dry) end of his curve, Gardner exposed both wet and dry 
filter papers to sulfuric acid solutions in an evacuated chamber. For the high water potential (wet), he used the relation of the capillary tension to the centrifugal force to get the potential. The filter paper was treated with 0.2 percent $\mathrm{HgCl}_{2}$ to avoid the decomposition of the paper by soil microorganisms. He concluded that after a curve has been determined for the filter paper, the method is neither complicated nor difficult.

The filter paper method for estimating water potential of soils has been modified by McQueen and Miller (1968). They claim it gives reasonable results over the entire range of soil water from saturation to dry air. They used the same basic concepts proposed by Gardner, but details of the method have been changed. For calibration at low water potential below -15 bars, the filter papers were exposed to saturated salt solutions in closed chambers in a constant temperature chamber. At higher water potentials soil samples were brought to a given potential on a pressure plate. The filter paper was placed in the top of each soil sample and the container was sealed with plastic insulating tape. All calibration samples were held in a constant temperature chamber at $20^{\circ} \mathrm{C}$ for equilibration. The filter papers were pretreated with pentochlorophenol 2 percent in ethanol to prevent microbial action.

\section{Other Methods of Measuring Water Potential}

\section{Tensiometer}

Marshall (1959) said, "The tensiometer is the only tool available for measuring suction directly in the field." Richards (1928), Heck (1934) and Rogers (1935) published papers which suggested the use of tensiometers to measure soil matric potential. These instruments are 
widely used in the field to determine when to irrigate, etc. In laboratory experiments where better precision is desired, Null type tensiometers have been devised by Miller (1951) and Leonard and Low (1962) which require no intercharge of water to follow changes in the soil water system. The tensiometer has somewhat limited usefulness because its range is limited on the dry end to -.8 bars matric potential and it is influenced by temperature gradients within the instrument.

\section{Pressure membrane}

The pressure membrane apparatus has long been used for measuring matric potential of soil at various soil moisture contents, i.e., for determining the water release curve of soils (Richards, 1941; Woodruff, 1941; and Reitmeier and Richards, 1944). It has been useful for studying the matric potential of soils and other materials, and for calibration of soil moisture instruments (Richards, 1947). This apparatus is similar in principle to the tensiometer but is usable only in the laboratory where water has to be removed as added to the soil and its range is limited to about 0 to -10 n bars.

\section{Electrical resistance units}

Resistance blocks made of various kinds of gypsum, nylon, fibreglass and plaster with nylon and fibre-glass around the electrodes have been used for measuring soil water. The gypsum block developed by Bouyoucos and Mick (1940) has been widely used for field studies in both agricultural and engineering problems. It has an advantage over nylon and fibre-glass blocks in that these are very sensitive to the effect of solutes on electical conductivity (Weaver and Jamison, 1951). It has a number of disadvantages. It is insensitive in wet soil and the 
buffering effect for salts, does not extend beyond low salt concentrations (Richards and Campbell, 1950). Also, as noted by Bouyoucos and Mick (1947), the life of a gypsum block is limited in wet soil due to the solubility of the gypsum. Thus, the calibration curve may change with time and this is difficult to check. Further, there is considerable hysteresis between the drying (release) curve and the wetting (intake) curve for the resistance-potential relation (Tanner and Hanks, 1952).

\section{Thermocouple psychrometer}

Theory. Scientists realized for many years that water potential can be inferred accurately from measurement of relative humidity. At any given temperature, $\mathrm{T}$, the theoretical relation between water potential and relative humidty is

$$
\psi=\frac{\mathrm{RT}}{\mathrm{V}} \ln \frac{\mathrm{e}}{\mathrm{e}_{0}}
$$

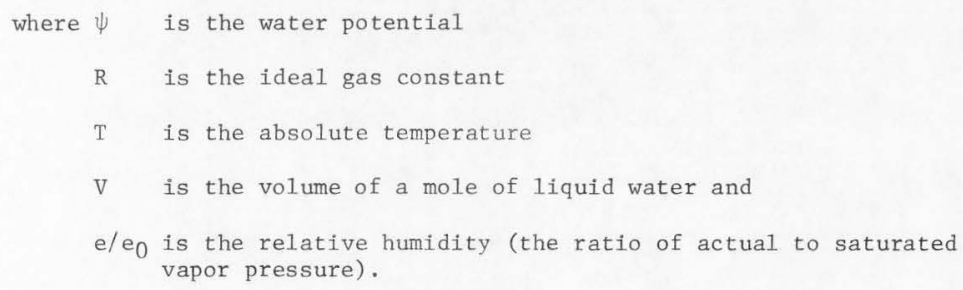

The only assumption involved in this relation is that water vapor behaves as an ideal gas, which introduces negligible error for the pressure normally encountered.

Thomas (1921) estimated the water vapor pressure in three different soils. His method consisted in passing a known volume of air through the soil, and collecting and weighing the vapor. He found that the 
vapor pressure was a linear function of the reciprocal of the moisture content over a wide range. This method is inaccurate in the range of water potential found in most soils because the relative humidity varies from only 98 to 100 percent in this range. In the fifties, accurate and convenient methods for measurement of vapor pressure in the range of 98-100 percent relative humidity were suggested by Spanner (1951), Monteith and Owen (1958), Richards and Ogata (1958), and Korven and Taylor (1959). The psychrometer required frequent calibration (Ehlig, 1962) and the results were not the same for different calibrations and different psychrometers. The recent comprehensive review by Barss (1968) cites over 50 references on the use of the Spanner psychrometer and related vapor exchange methods. However, from this and other reviews (Rawlins, 1966; Peck, 1968-1969; Boyer, 1969 and Brown, 1970) there still appears to be the need for a practical guide on the use of thermocouple psychrometers and other methods of measuring water potential and its components (Wiebe et al., 1971).

The Peltier-type ceramic covered thermocouple psychrometer has found many applications because it is convenient to use in field psychrometers (Rawlins and Dalton, 1967) where it would be difficult to remove a wet-1oop psychrometer to add a water droplet, and because it is relatively free from measurement errors arising from the addition or removal of water from the system (Zollinger et al., 1966). 
MATERIALS AND METHODS

The basic concept of using filter paper for estimating soil water potential proposed by Gardner (1937) has been followed by McQueen and Miller (1968), but details of the method have been changed to eliminate some of the errors and difficulties.

\section{Apparatus and supplies}

1. The equipment required for routine gravimetric soil moisture tests.

2. An analytical balance, accurate to $0.0002 \mathrm{gm}$.

3. Sma11 1ight-weight moisture cans.

4. Constant temperature room.

5. Adjustable temperature chamber.

6. An insulated box (foam ice chest).

7. Filter paper - Schleicher and Schue11 No. 589 white ribbon, $51 / 2 \mathrm{~cm}$ diameter.

8. Pentochlorophenol "Dowcide-7" reagent grade or equivalent.

9. Ethanol or methanol reagent grade solvent.

10. Plastic electrical tape to seal soil moisture can.

11. Towel paper (Type 900-S, Kim towels) and polyethylene sheet.

\section{Soil samples}

Soil samples were taken from two different kinds of soil, Nibley silty clay loam and Mesa sandy loam, whose particle size distributions are given in Table 1. 


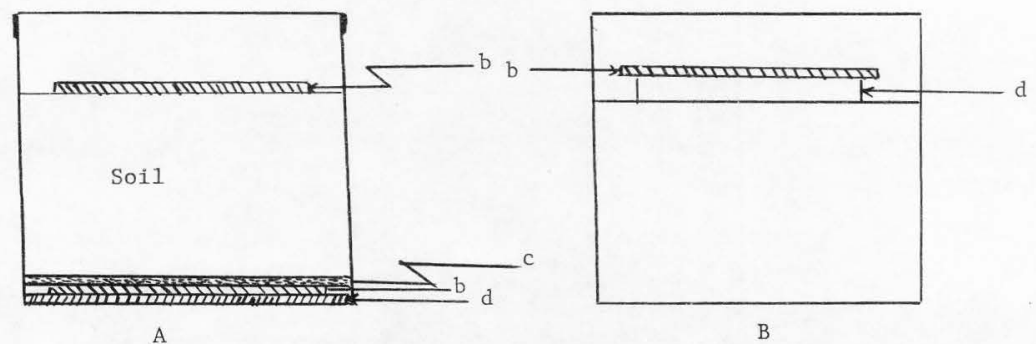

A

No contact

Uncertain contact

Good contact

a - Polyethylene sheet

b - Filter paper Sand S No. 5895.5 in. dia.

c - Paper towe1

d - Brass cylinder

Figure 1. Diagram of equipment used to measure soil water potential. Also shows types of contact between filter paper and soil samples. 
Table 1. Particle size distribution of Nibley clay loam and Mesa sandy loam ${ }^{1}$

\begin{tabular}{lrcccc}
\hline & $\begin{array}{l}\text { Depth } \\
\text { inches }\end{array}$ & Horizon & $\%$ sand & $\%$ silt & \% clay \\
\hline Nibley silty & $7-11$ & A12 & 3.9 & 59.3 & 36.8 \\
clay loam & $11-19$ & B12 & 3.5 & 59.6 & 36.9 \\
Mesa sandy loam & $0-12$ & & 56 & 30 & 14 \\
& $12-24$ & & 48 & 29 & 23 \\
\hline
\end{tabular}

Mesa sandy loam. This sample was collected from the Hullinger farm near Verna1, Utah. This farm is located just west of the Vernal Airport, 1.5 miles south and 0.6 miles east of Vernal city center. This soil has not been classified yet, thus the name is not official and is used for convenience only.

Nibley silty clay loam. This sample was collected from the Utah State University South Farm located between Logan and Hyrum. The soil has been classified but data not published. ${ }^{2}$ The information is available at Utah State University in the Department of Soil Science and Biometeorology.

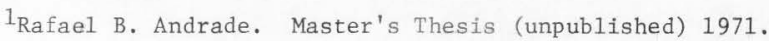

${ }^{2}$ A. Southard, Personal communication. Department of Soil Science and Biometeorology, Utah State University, Logan, Utah. 


\section{PROCEDURE}

The following general procedure was used. Exceptions to this procedure were made where appropriate for a particular test.

1. Filter paper discs (5 $1 / 2 \mathrm{~cm}$ diameter) were pretreated to inhibit biological decomposition and to minimize bacterial growth by dipping them in a 3 percent solution of pentochlorophenol "Dowcide-7" in ethanol and allowing to air dry overnight as discussed by McQueen and Miller (1968).

2. One treated filter paper was placed on the top and/or another one on the bottom of each soil sample. The can was sealed with plastic insulating tape. The filter paper was placed underneath each soil sample in order to improve the contact with soil. A piece of polyethylene sheet was placed under the filter paper and paper towel was placed over the filter paper. The paper towel allowed the water to flow through it and kept the soil particles from clinging to the filter paper. The polyethylene was used to avoid the deposit of the rust on the filter paper from the moisture can. The soil samples weighed about $100 \mathrm{gm}$. At high water potentials (wet) the filter paper absorbed about $0.1 \mathrm{gm}$ of water.

3. The samples were placed in an insulated box in a constant temperature room and allowed to equilibrate for several days.

4. After equilibration the filter paper was removed from the soil sample can, placed in a weighing can and its moisture content accurately determined, using the analytical balance. 
5. The water potential of soil samples was measured by four methods.

(a) Sample chamber psychrometer C-51. (The Wescore Mode1 C-51 sample chamber psychrometer is designed to measure water potential of small samples in the laboratory or in the field without a constant temperature bath. The placing of the sample holder under the thermocouple is by means of a slide; the chamber is then sealed. The reading can be made after allowing for equilibration, then another sample can be inserted from the opposite side. Wescor, Inc., 459 South Main Street, Logan, Utah, 84321). The thermocouple psychrometer has a range of -1 to -50 bars.

(b) For water potential from -15 to -0.1 bars, samples were brought to given water potential levels on a pressure membrane extractor. Calibration for potential levels higher than -0.1 bar was determined from samples obtained at a known height above a water table. Two soil columns were set up in the laboratory and allowed to reach equilibrium for two weeks. Water potential was found by measuring the distance between the water table and the point of sampling. Also, salt solutions were used in calibration of the filter paper method $(-1.4$ bars to 22.4 bars).

In order to determine the moisture content of the filter paper accurately, transference of the filter paper from the soil sample container to the weighing box must be done as rapidly as possible and with as little contact of the filter paper with hand and tools (forceps) as possible. If there are sand grains clinging to the paper, they 
should be quickly flipped off. The wet weight of the paper should be obtained immediately because evaporation is rapid in dry laboratory air. Drying time is normally overnight, but it can be shortened to 6-8 hours if necessary. The lids of the cans should be closed upon removal of the boxes from the oven and placed for 30 seconds to cool and then they are weighed immediately, the weight of the can is obtained before the filter papers can absorb a weighable quantity of moisture (McQueen and Miller, 1968).

The filter papers were equilibrated under conditions and procedures that were as much as possible like those that exist during normal use of the method. However, additional conditions and procedures were investigated to help define limits of accuracy and time requirement for equilibration.

Temperature effect. McQueen and Miller (1968) calibrated the filter paper in a constant temperature chamber held at $20^{\circ} \mathrm{C} \pm 1^{\circ} \mathrm{C}$. Tests were made in the temperature chamber held at 15, 20, 24, 32 and no temperature control provided. The temperature fluctuation in the room was about $\pm 2^{\circ} \mathrm{C}$. An insulated box (foam ice chest) was also used to decrease temperature fluctuation. Theoretically, there should be no significant difference between these temperature treatments, because there is competition between the filter paper and the soil for the water.

Contact effect. With this method there is a possible problem with contact between the soil and the filter paper. In the method of Miller and McQueen (1968) the filter paper is simply placed on the soil which results in an uncertain contact. This is important because the filter paper may wet to a different water content if there is significant 
liquid flow from the soil to the filter paper than if there is only vapor flow. A detailed discussion of the contact effect will be given later on. Three types of contacts were tested to study the effect of contact between filter paper and soil samples. The type of contacts were (1) uncertain contact, which was carried out by placing the filter paper on the soil sample; (2) good contact, in which the filter papers were placed underneath the soil sample; and (3) no contact, which was carried out by placing rubber moisture rings or brass rings between the filter paper and the soil sample to insure no liquid flow between soil and filter paper. 


\section{RESULTS AND DISCUSSION}

Table 2 shows an evaluation of the time required for equilibration. The samples were all held on a brass cylinder so the filter paper was not in contact with soil. This would probably be the slowest equilibration for all treatments. These data show that equilibration was essentially complete by the end of two days and certainly by the end of five days. There was a slightly larger filter paper water content where the soil water was 0.10 compared to 0.05 apparently due to the differences in the water potential between the two soil samples. The size of the sample did not appear to have any influence on the results.

Table 2. Effect of type of equilibration environment, water content, sample size and water content at time of equilibration on the water content (by weight) of the filter paper. Mesa sandy loam. Filter paper not in contact with soil

\begin{tabular}{lccccc}
\hline & \multicolumn{5}{c}{ Equilibrated in constant temperature room } \\
\cline { 2 - 6 } W soil & Sample size & 2 days & 5 days & 7 days & 9 days \\
\hline 0.05 & 50 & 0.37 & 0.38 & 0.37 & 0.37 \\
0.10 & 50 & 0.40 & 0.42 & 0.42 & 0.44 \\
0.05 & 100 & 0.39 & 0.41 & 0.40 & 0.41 \\
0.10 & 100 & 0.40 & 0.42 & 0.43 & 0.42 \\
0.05 & 150 & 0.36 & 0.37 & 0.36 & 0.37 \\
0.10 & 150 & 0.45 & 0.48 & 0.47 & 0.47 \\
\hline
\end{tabular}


McQueen (personal communication) said that the filter paper had to be in contact with soil. Until that time contact had been avoided because this confuses what the filter paper was measuring. With good contact the filter paper would probably measure only matric potential and not be sensitive to the osmotic potential. Without contact the filter paper would measure the sum of the osmotic and matric potential. In response to this suggestion, another experiment was conducted using the same samples as in Table 2 except that the filter paper was placed in the soil in loose contact with the soil sample. Table 3 gives these results. The data show equilibrium to have taken place by the end of the first day. The data are more erratic than that of Table 2. The filter paper water contact with the soil at a water content of 0.05 was lower or equal to that without contact. However, the reverse was true for a soil water content of 0.10 .

Table 3. Same as Table 2 except filter paper in contact with soil

Equilibrated in constant temperature room

Equilibration time

\begin{tabular}{lccccccc}
\cline { 3 - 5 } W soil Sample size & 1 day & 2 days & 3 days & 4 days & 5 days & 7 days \\
\hline gm & 50 & 0.32 & 0.32 & 0.32 & 0.29 & 0.30 & 0.30 \\
0.10 & 50 & 0.48 & 0.52 & 0.51 & 0.48 & 0.48 & 0.51 \\
0.05 & 100 & 0.34 & 0.33 & 0.33 & 0.33 & 0.32 & 0.33 \\
0.10 & 100 & 0.52 & 0.52 & 0.54 & 0.52 & 0.52 & 0.53 \\
0.05 & 150 & 0.40 & 0.38 & 0.37 & 0.38 & 0.39 & 0.38 \\
0.10 & 150 & 0.47 & 0.48 & 0.50 & 0.49 & 0.48 & 0.49 \\
\hline
\end{tabular}

Where $W$ soil = fractional water content of the soil by weight. 
The data of Table 4 were collected because it was noticed that water condensed on the can lids for the wetter soils in the constant temperature room, but to a much smaller extent when the insulated box was used. The data show a higher water content in all cases where equilibrium occurred in the constant temperature room only.

Table 4. Influence of type of equilibrium environment on the filter paper water content $(\theta)$ as a function of sample size and soil water content. Filter paper taped to lids of cans - not in contact with soil

\begin{tabular}{cccc}
\hline W soil & Sample size & $\begin{array}{c}\text { Filter paper } \\
\text { const. temp. room }\end{array}$ & $\begin{array}{c}\text { Filter paper } \\
\text { ins. box }\end{array}$ \\
\hline .05 & 50 & .34 & .29 \\
.10 & 50 & .39 & .33 \\
.15 & 50 & .46 & .34 \\
.05 & 150 & .33 & .28 \\
.10 & 150 & .42 & .36 \\
.15 & 150 & .48 & .39 \\
\hline
\end{tabular}

\section{Temperature effect}

One of the objectives of this study was to find the influence of temperature and temperature variation on the relation of filter paper water content to soil water potential. Calibration of the filter paper at constant temperature $20^{\circ} \mathrm{C} \pm 1^{\circ} \mathrm{C}$ was used by McQueen and Miller (1968). Two constant temperature rooms which control the temperature within about $\pm 2.0^{\circ} \mathrm{C}$ were used. There were considerable problems associated with drops of water condensing inside the cans. These problems were particularly serious for high water potential (above -15 bars). This 
problem was solved by placing the samples inside an insulated box (foam ice chest) which was, in turn, placed in the constant temperature room. The temperature fluctuation inside the insulated box was less than $\pm 0.1^{\circ} \mathrm{C}$.

The data, plotted on semi-logarithmic paper for the four temperature treatments for the uncertain contact (filter paper on top of soil), are shown in Figure 2 .

The formulas for the different lines are:

1. Temperature $=15^{\circ} \mathrm{C} \quad \log _{10}(-\psi)=2.5143-0.047 \theta$

2. Temperature $=20^{\circ} \mathrm{C} \quad \log _{10}(-\psi)=2.7873-0.0579 \theta$

3. Temperature $=24^{\circ} \mathrm{C} \quad \log _{10}(-\psi)=2.5272-0.0504 \theta$

4. No temperature control $\log _{10}(-\psi)=3.0703-0.0676 \theta$

Where $\psi$ is the soil water potential in bars and $\theta$ is the water content of the filter paper in percent of dry weight.

The statistical analysis shows that there was no significant difference between the temperature treatments at 95 percent confidence interva1.

The data for good contact (filter paper beneath the soil), plotted on semi-logarithmic paper for the five temperature treatments, are shown in Figure 3.

The formulas for the different lines are:

$$
\begin{array}{ll}
\text { 1. Temperature }=15^{\circ} \mathrm{C} & \log _{10}(-\psi)=2.1516-0.0366 \theta \\
\text { 2. Temperature }=20^{\circ} \mathrm{C} & \log _{10}(-\psi)=2.666-0.0579 \theta \text { (Repeated) } \\
\text { 3. Temperature }=24^{\circ} \mathrm{C} & \log _{10}(-\psi)=2.1115-0.030 \theta \\
\text { 4. Temperature }=32^{\circ} \mathrm{C} & \log _{10}(-\psi)=2.132-0.034 \theta \\
\text { 5. No temperature control } & \log _{10}(-\psi)=2.256-0.036 \theta
\end{array}
$$




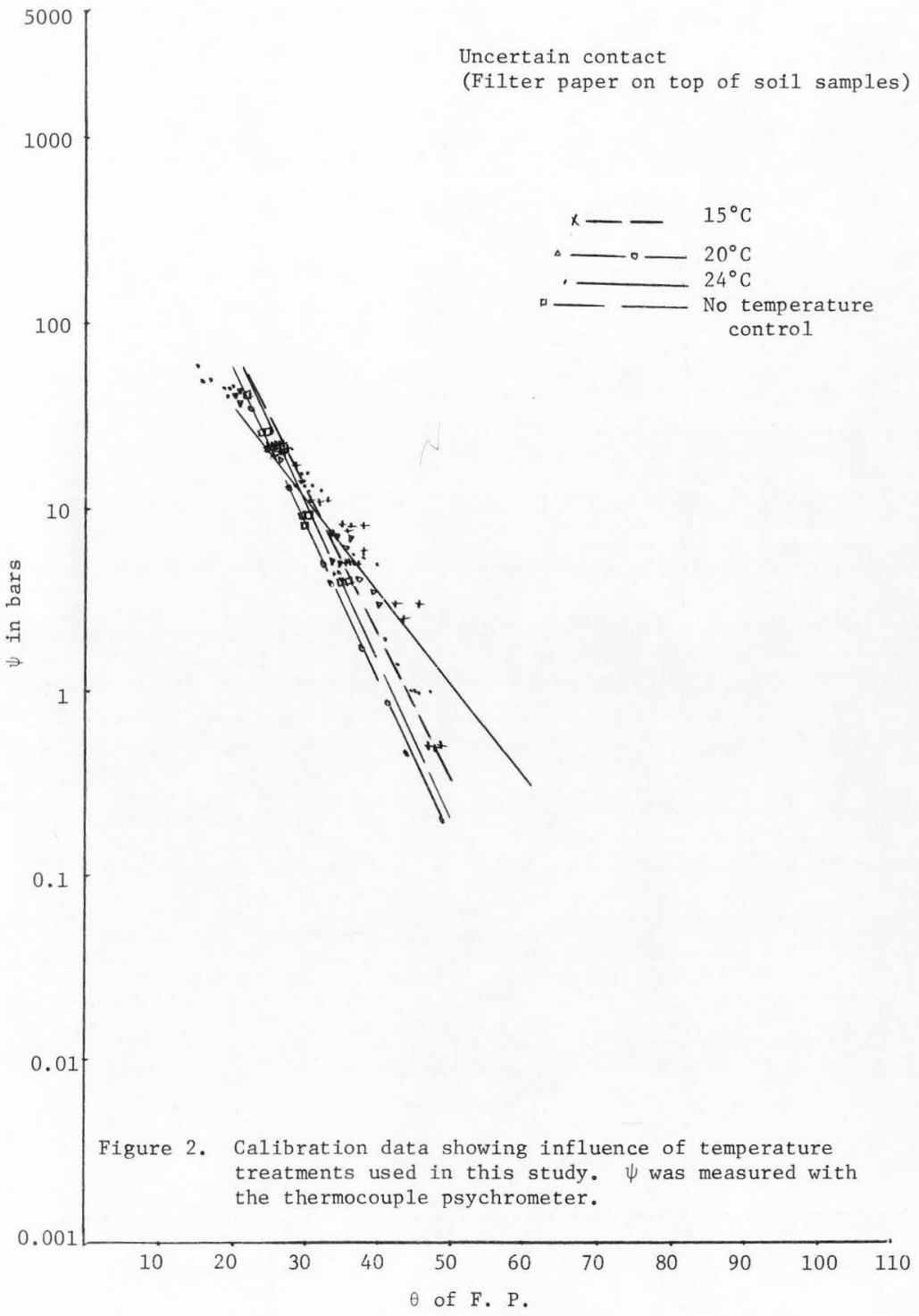




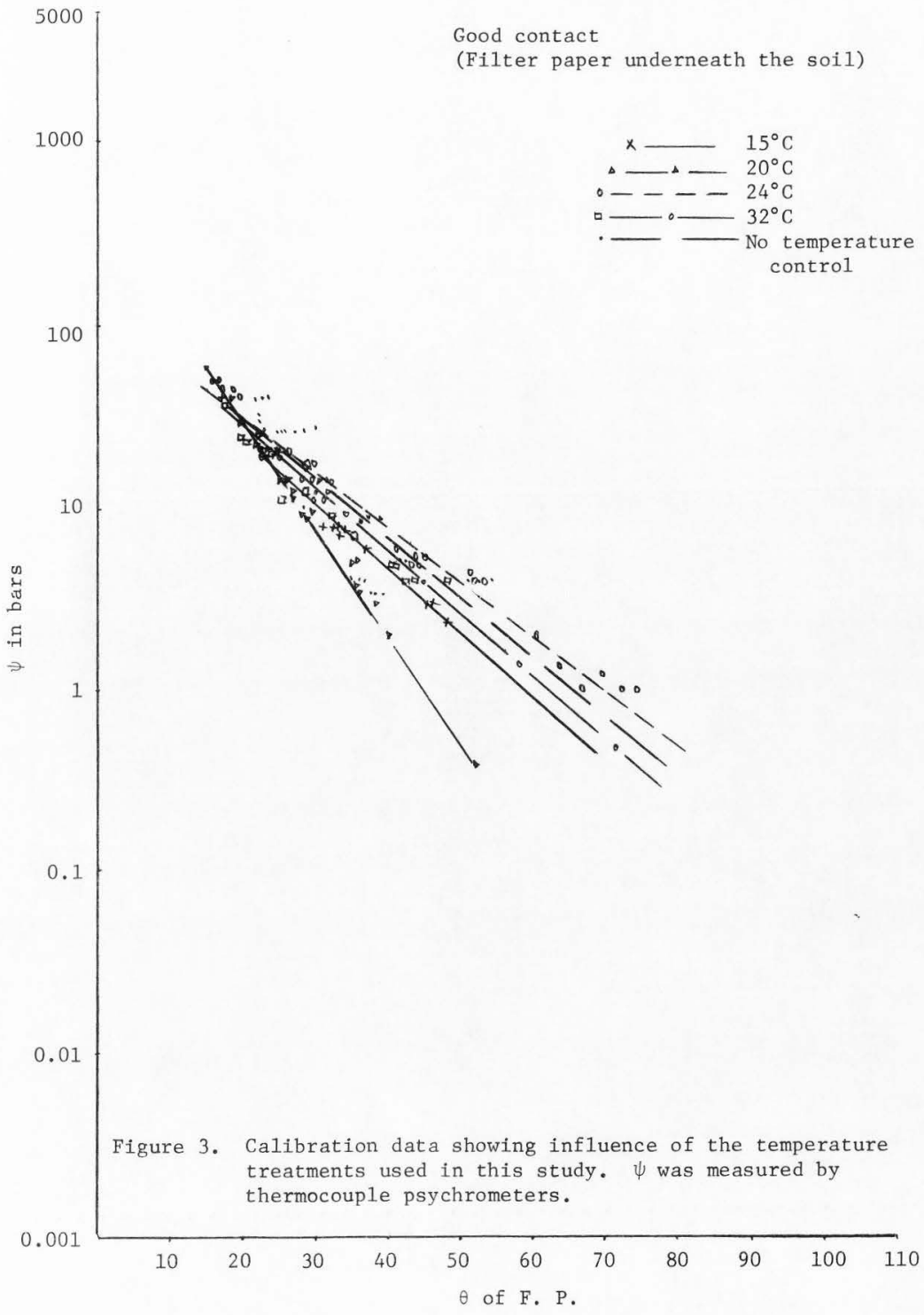


The statistical analysis shows that there was no significant differences between temperature treatments $\left(15,24\right.$, and $32^{\circ}$ and no temperature control) at 95 percent confidence limits. But there was significant differences between the temperature treatment at $20^{\circ} \mathrm{C}$ and temperature treatments at 24 and $32^{\circ}$ and no temperature control. This is due to unexplainable factors at the present time.

\section{Uncertain contact}

All of the results from $15,20,24^{\circ} \mathrm{C}$ and no temperature control (given in Tables $5,6,7$ and 8 in the appendix) were pooled and all data were plotted on semi-logarithmic paper and the best fit was found to be the straight line using regression analysis techniques (Figure 4). The formula for the line is:

$$
\log _{10}(-\psi)=2.657-0.054 \theta,
$$

where $\psi$ is water potential in bars, $\theta$ is moisture content of the filter paper in percent of dry weight.

Figure 4 also shows a comparison between the calibration line published by McQueen and Miller (1968) and the line obtained during this investigation. The statistical analysis shows that there are significant differences between these two lines, but the difference appears to be small. The shifting in the line made a difference in the reading of $\psi$ with a range of -1 bar at the wet end and +10 bars at the dry end. The statistical analysis shows that there were significant differences between the data from uncertain contact and data from good or no contact. The data at the very wet end of this scale will be discussed later with a good contact. 


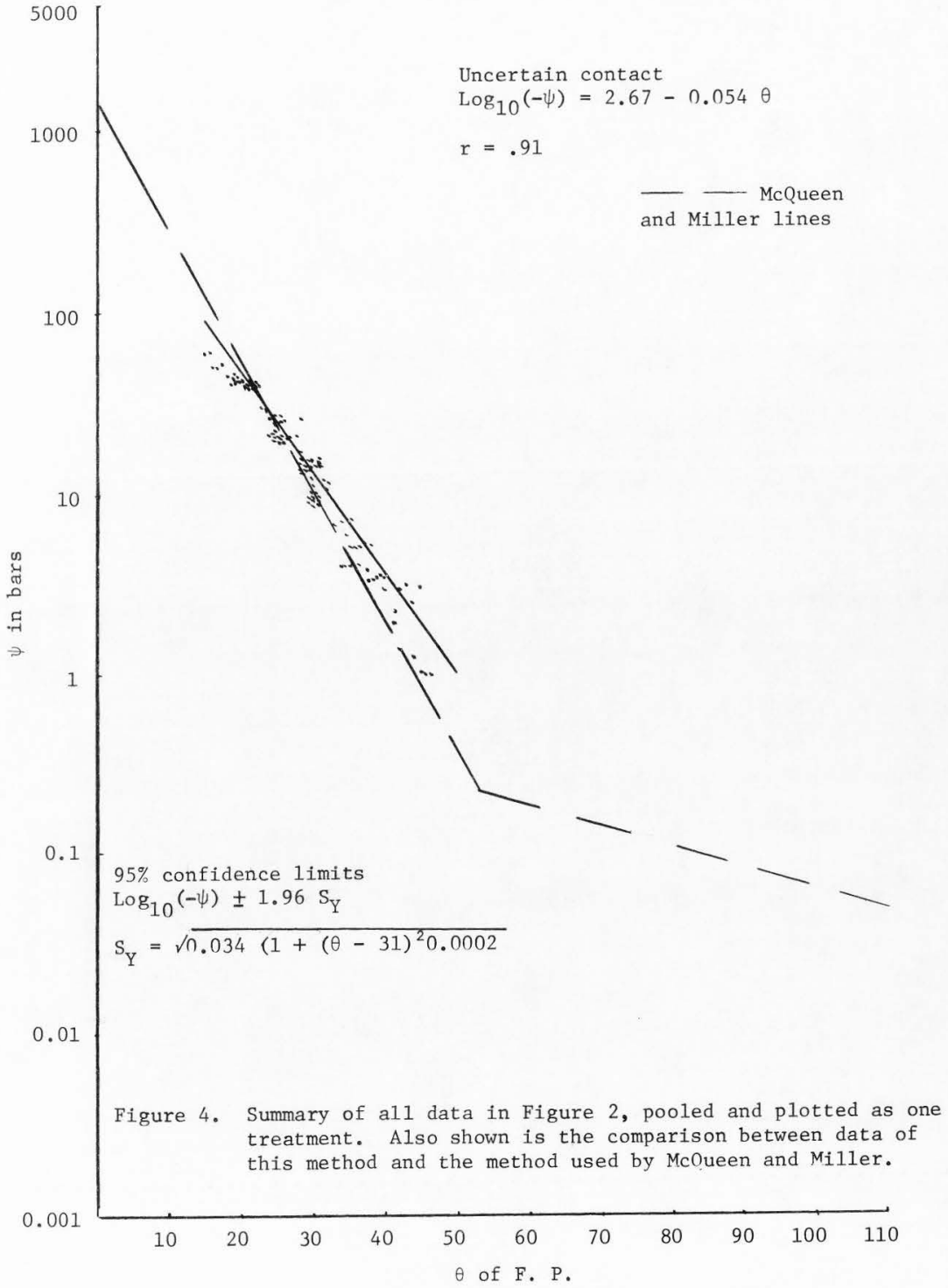




\section{Good contact}

Al1 the calibration data were collected under the same conditions as uncertain contact except the filter papers were placed underneath the soil samples as described earlier. Technical data for this phase of calibration are given in Tables 5, 6, 7, 8, and 9 in the appendix. The pooled results were plotted on semi-logarithmic paper and the best fit was found to be a straight line as shown in Figure 5. The formula for the line is

$$
\log _{10}(-\psi)=2.1355-0.0337 \theta \text {. }
$$

The statistical analysis shows that there was significant difference between the data from uncertain contact and the data for good contact. Probably this occurs because there are differences in liquid flow, particularly at the wet end where the filter paper may measure different things depending on contact. Calibration for high water content ( $\psi \geq-0.1$ bars) was determined from samples obtained at known heights above a water table (as discussed earlier). The data are shown in Figure 6 and are in Table 11 in the appendix. The statistical analysis shows that there is no significant difference between the data for uncertain contact between the filter paper and soil samples and the data for good contact for water potential between -0.1 and -0.01 bars . The data are plotted on semi-logarithmic paper in Figure 6 . the formula for the line is

$$
\log _{10}(-\psi)=0.0021-0.009 \theta \text {, }
$$

where $\psi=$ water potential, and $\theta=$ water content of the filter paper percent in dry weight. 


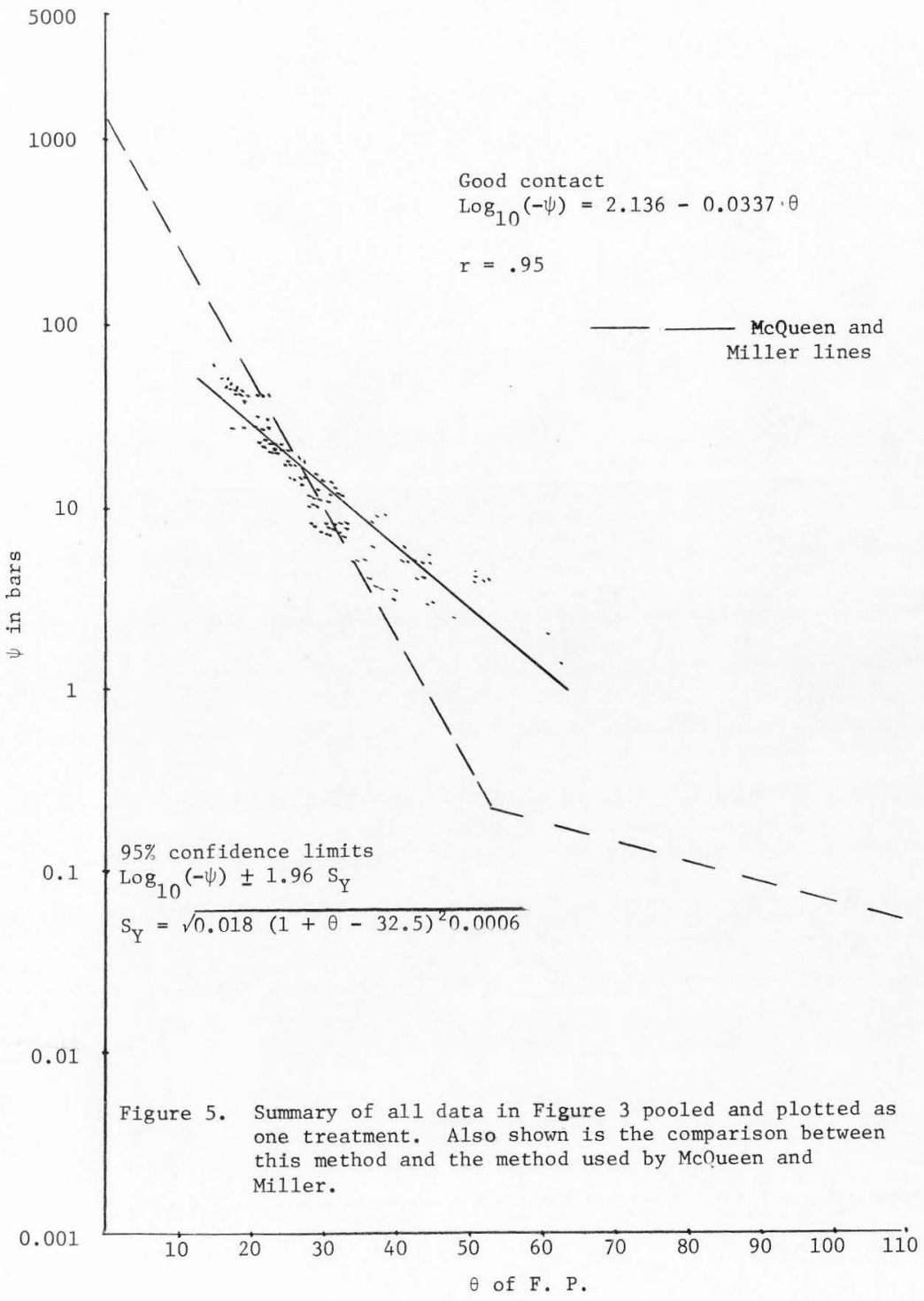




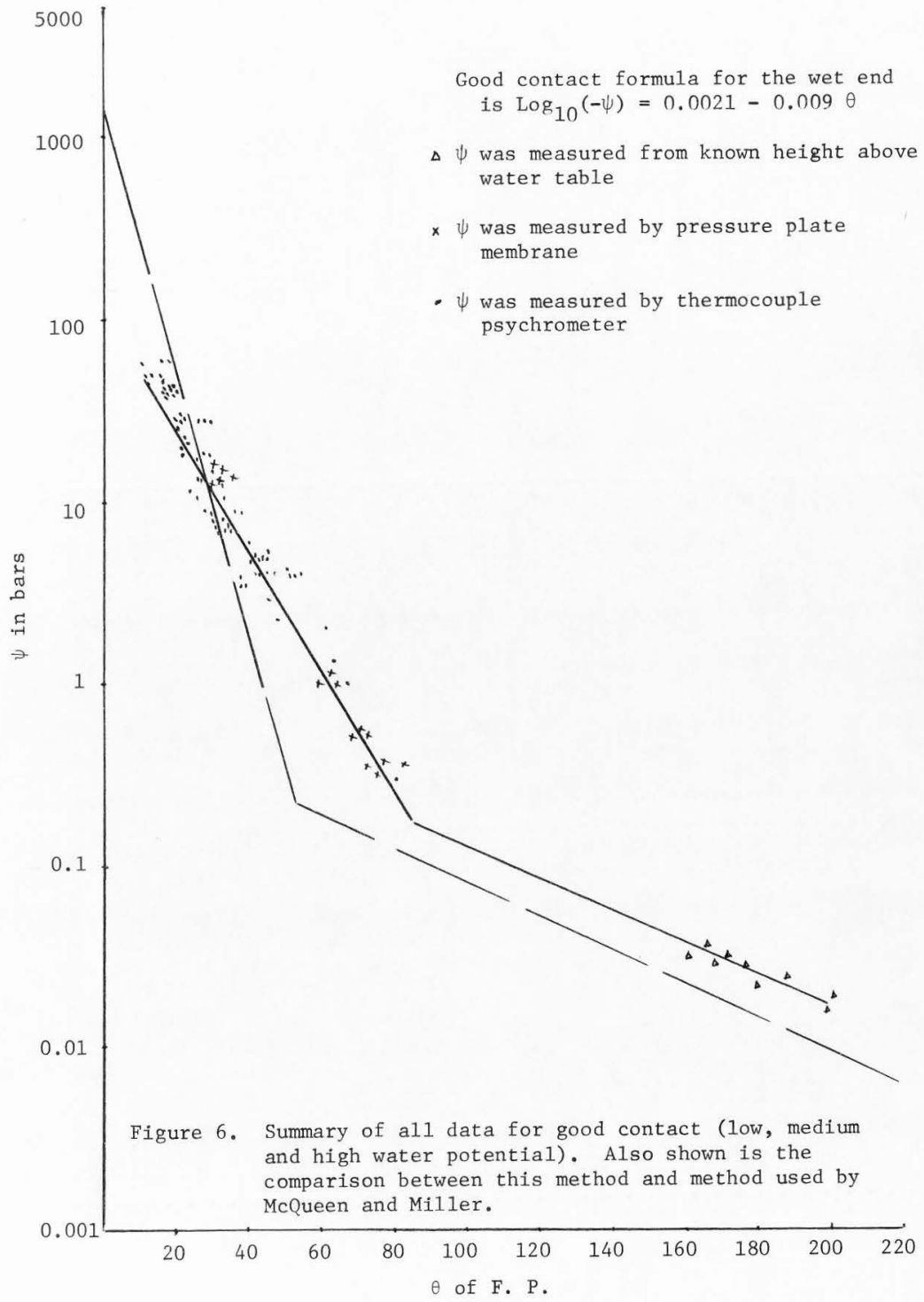


Also Figure 6 shows the intersection point between the two lines in Figures 5 and 6 . The intersection point is near the field capacity potential values -0.1 to -0.3 bars. Gardner (1956), in discussing capillary conductivity, said that conductivity of the soil becomes limiting at about -0.15 to -0.2 bars. Figure 5 also shows a comparison between the curves of good contact and McQueen and Miller's (1968) curve. Figure 7 also shows a comparison curve of uncertain contact and McQueen and Miller's (1968) curves.

Figure 8 shows a comparison between the calibration curve published by Gardner (1937) and the line obtained during this investigation (good contact). The results are approximately similar within a range of $\psi$ from -1 bar to -50 bars. Gardner's curve is within 95 percent confidence limits of the line found in this experiment. Gardner said of his curve: "The upper portion (low water potential) of the curve is no doubt somewhat above the true value, as only drying papers were used."

\section{No contact}

Al1 the calibration data were conducted under the same conditions as in the previous trials except the filter papers were separated from the soil samples by a rubber ring. Also another trial was carried out by exposing the filter paper to KCl solution rather than soils in a closed container in the constant temperature chamber. The results are in Tables 12 and 13 in the appendix. All the results were plotted on semi-logarithmic paper and the best fit was found in the straight line in Figure 9. Formulas for the lines are:

$$
\text { For the soil: } \log _{10}(-\psi)=3.4098-0.0725(\theta) \text {, }
$$




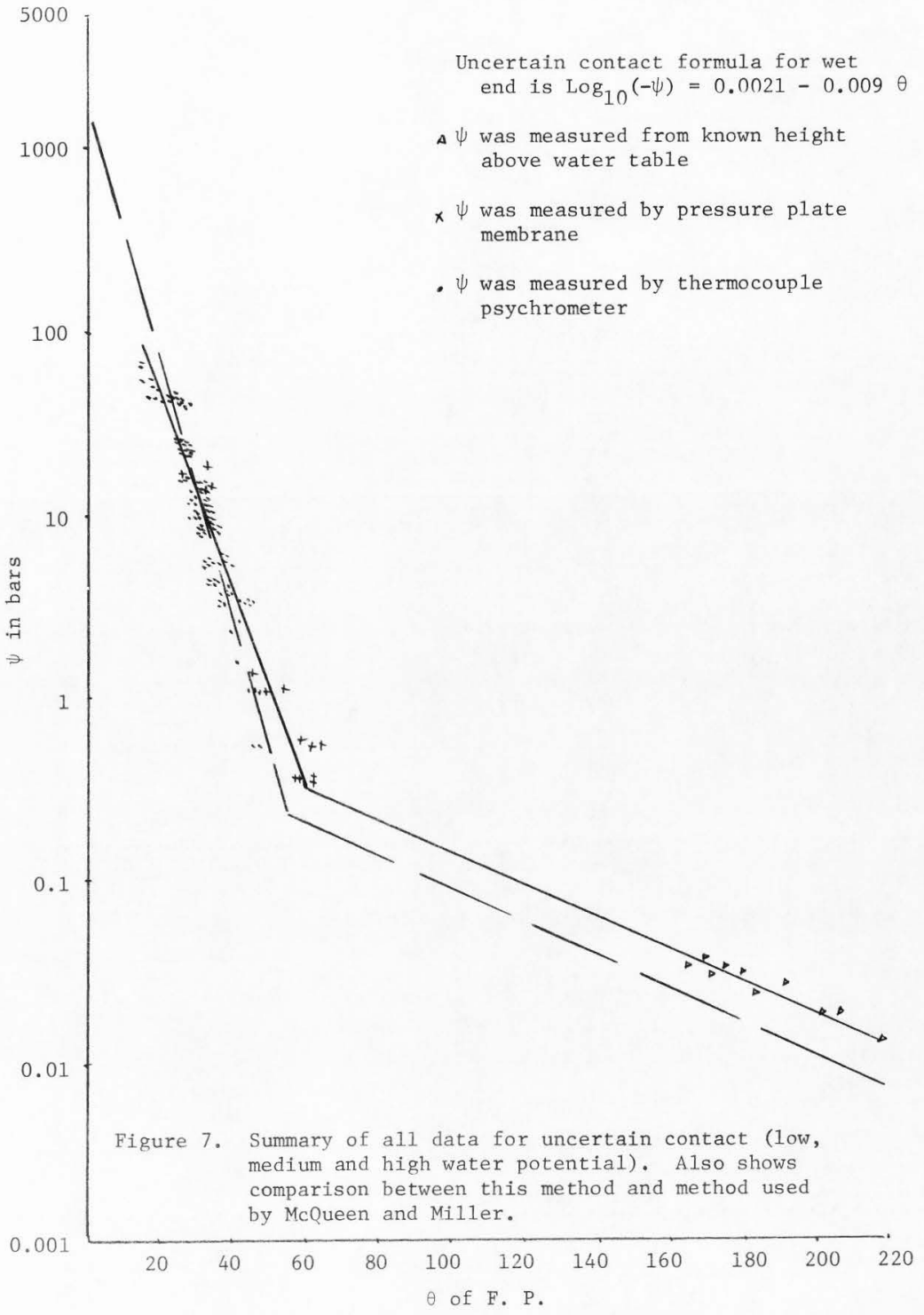




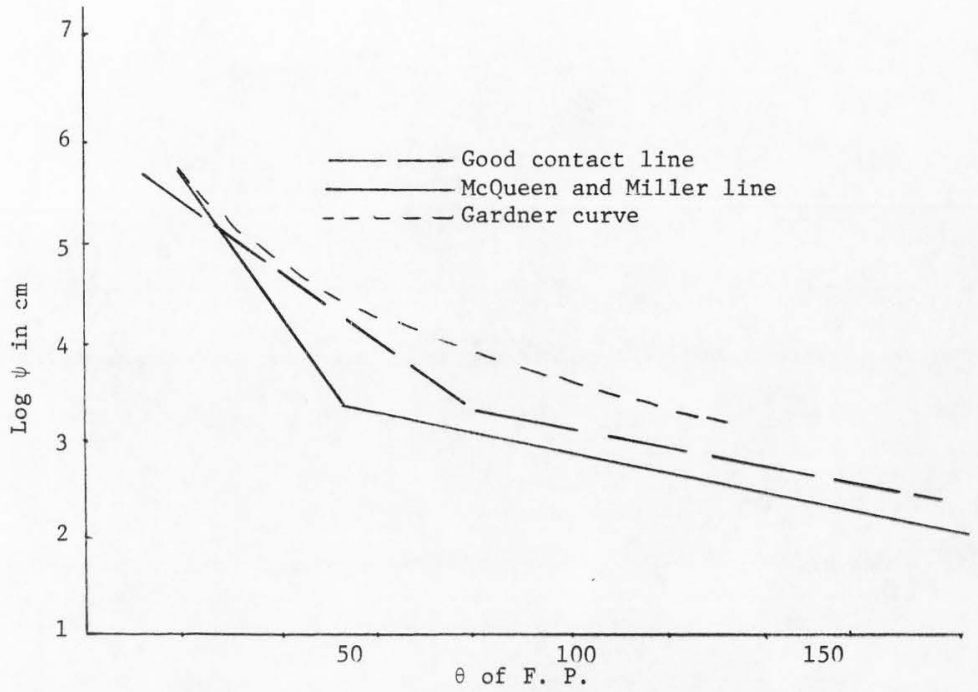

Figure 8. Summary of data (good contact) showing comparison among the methods used in this study, the McQueen and Miller and the Gardner method. 


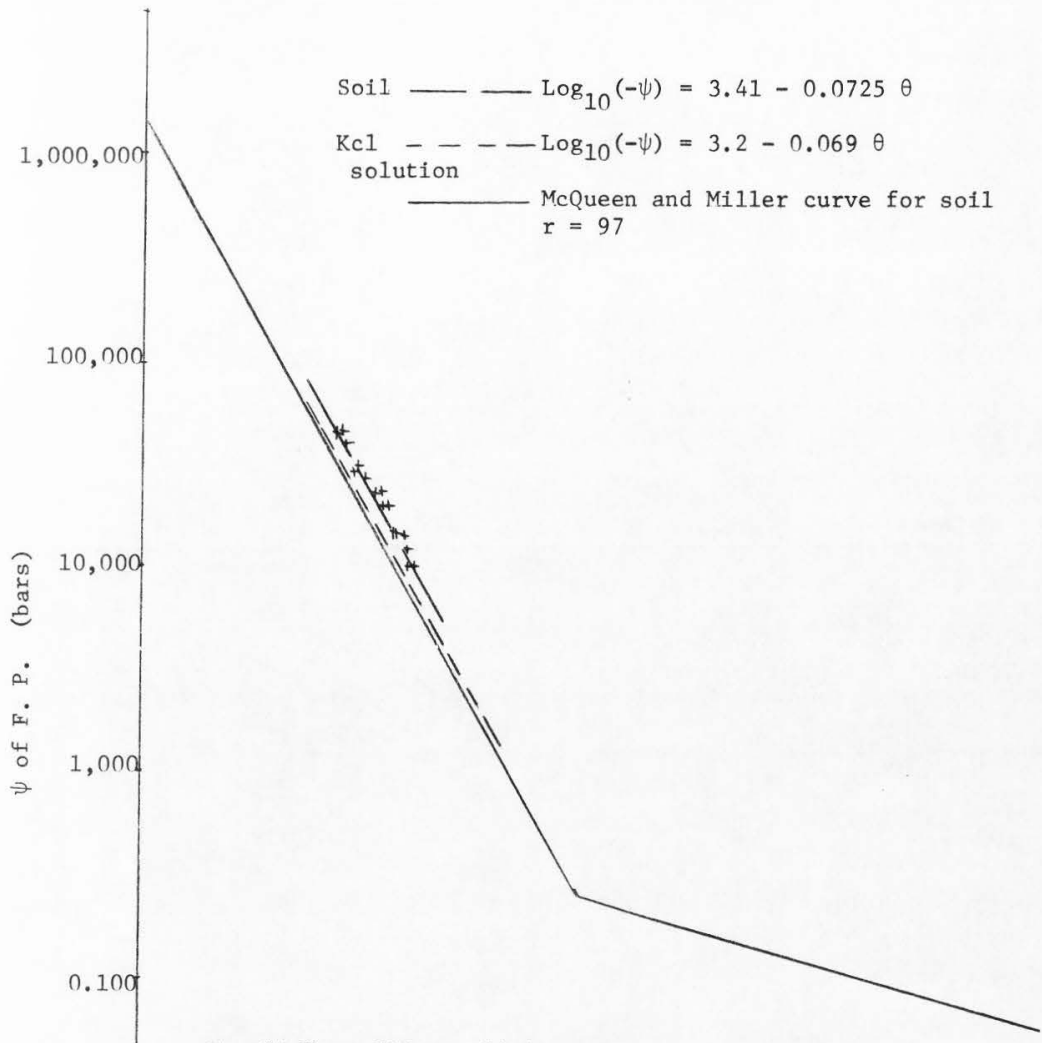

For $95 \%$ confidence limits

$\log _{10} \psi \pm 2.0 \mathrm{~S}_{\mathrm{Y}}$

$0.010 \quad \mathrm{~S}_{\mathrm{Y}}=\sqrt{0.006\left(1+(\theta-28.9)^{2} 0.004\right.}$

Figure 9. Summary of calibration data showing comparison between two methods used in this study (no contact, salt solution for calibration) and method used by McQueen and Miller.

20

20

$30 \quad 40$

$\theta$ of F. P. (percent of dry weight) 
For the KC1 solution: $\log _{10}(-\psi)=3.1997-0.0692(\theta)$.

The statistical analysis shows that there is no significant difference between these two lines in Figure 9 and McQueen and Miller's curve. Moisture movement into the filter paper was by vapor diffusion only. All measurements were made with the thermocouple psychrometer and sample charger. 
SUMMARY AND CONCLUSIONS

1. The objectives of this method were to test the filter paper method of estimating soil water potential over a wide range of soil water potential.

2. Calibration of the method was accomplished in the laboratory using saturated salt solutions, sample chamber psychrometers, pressure membrane extractors and equilibrium above the water table.

3. Type of contact has a marked effect on the relation between filter paper water content and soil water potential. It is suggested that one filter paper be placed beneath the soil (good contact for liquid flow and vapor flow) and one filter paper be placed above the soil not in contact with soil (allowing vapor flow only).

4. It was concluded that the temperature fluctuation should be small.

5. It was concluded that the absolute temperature was not too important.

6. The equilibrium between the filter paper and soil mass was essentially complete by the end of two days and certainly by the end of five days.

7. Comparison was made between McQueen and Miller's (1968) calibration and the calibration used herein where the filter paper was placed on the soil sample (considered uncertain contact). There was a small difference between the calibrations making a difference in reading of $\psi$ at the wet end of 1 bar and at the dry end of +10 bars. The reason for this shift may be caused by differences in the temperature fluctuation or variations in the degree of contact between soil and filter paper. 


\section{REFERENCES}

Barss, H. D. 1968. Determination of water deficits in plant tissue in water deficits and plant growth (T. T. Kozlowski, Ed.). Academic Press, New York. Vol. I, pp. 235-368.

Boersma, L., J. W. Cary, D. D. Evans, A. H. Ferguson, W. H. Gardner, R. J. Hanks, R. D. Jackson, W. D. Kemper, D. E. Miller, D. R. Nielsen, and G. Uehara. 1970. Soil Water. Western Regional

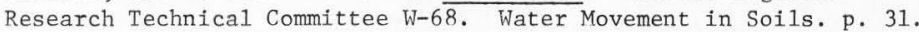

Bouyoucos, G. J., and Mick, A. H. 1940. An electrical resistances method for the continuous measurement of soil moisture under field conditions. Mich. Agric. Exp. Sta. Tech. Bul. 172.

Bouyoucos, G. J., and Mick, A. H. 1947. Improvement in the plaster of paris absorpiton block electrical resistances method for measuring soil moisture under field conditions. Soil Sci. 63:455-465.

Boyer, J. S. 1969. Measurement of the water status of plants. Ann. Rev. Plant Physiol. 20:351-364.

Brown, R. W. 1969. Leaf sampler for relative water content measurements: Design and application. Agron. J. 61:644-647.

Ehlig, G. F. 1962. Measurement of energy status of water in plant with a thermocouple psychrometer. Plant Physiol. 37:288-29n.

Gardner, Robert. 1937. A method of measuring the capillary tension of the soil moisture over a wide moisture range. Soil Sci. 43:277-283.

Gardner, W. R. 1956. Calculation of capillary conductivity from outflow data. Soil Sci. Am. Proc. 20:317-320.

Gardmann, M. 1934. Utber die Messung von Bodensaugwerten (About the measurement of soil suction): Jb Wiss Bot. 80:92-111.

Hansen, H. C. 1926. The water-retaining power of the soil. J. Ecol. 14:111-119.

Heck, A. F. 1934. A soil hygrometer for irrigated cane lands of Hawaii. J. Am. Soc. Agron. 26:274-278.

Korven, H. C., and Taylor, S. A. 1959. The peltier effect and its use for determining relative activity of soil water. Am. J. Soil Sci. 39: 79-83. 
Leonard, R. A., and Low, P. F. 1962. A self-adjusting null point tensiometer. Soil Sci. Am. Proc. 26:123-125.

Marsha11, T. J. 1959, Relations between water and soil. Tech. Pub1. No. 50. Commonwealth Bureau of Soils, Harpenden.

McQueen, I. S., and R. F. Miller. 1968. Calibration and evaluation of a wide-range gravimetric method for measuring moisture stress. Soil Sci. 106:225-231.

Miller, R. D. 1951. A technique for measuring tensions in rapidly changing systems. Soil Sci. 72:291-301.

Montieth, J. L., and Owen, P. C. 1958. A thermocouple method for measuring relative humidity in the range $95-100 \%$ J. Sci. Inst. $34: 443-446$.

Peck, A. J. 1968. Theory of spanner psychrometer. I. The thermocouple. Agr. Meteorol. 5:533-547.

Peck, A. J. 1969. Theory of spanner psychrometer. II. Sample effects and equilibration. Agr. Meteorol. 6:111-124.

Rawlins, S. L. 1966. Theory for thermocouple psychrometers used to measure water potential in soil and plant samples. Agr. Meteorol. $3: 293-310$.

Rawlins, S. L., and F. N. Dalton. 1967. Psychrometric measurement of soil water and potential without precise temperature control. Soil Sc1. Soc. Amer. Proc. 31:297-301.

Reitmeier, R. F., and Richards, L. A. 1944. The reliability of the pressure membrane method for extraction of soil solution. Soil Sci. 57:119-135.

Richards, L. A. 1928. The influence of capillary potential to soil moisture and plant investigators. J. Agr. Res. 37:719-742.

Richards, L. A. 1941. A pressure membrane extraction apparatus for soil suction. Soil Sci. 51:377-386.

Richards, L. A. 1947. Pressure membrane apparatus construction and use. Agr. Engin. 28:451-454, 460 .

Richards, L. A., and Campbel1, R. B. 1950. The effect of salinity on the electrical resistances of gypsum, nylon and fiberglass soil moisture measuring units. U. S. Dept. Agric. Reg. Salinity Lab. Res. Dept. 42.

Richards, L. A., and G. Ogata. 1958. A thermocouple for vapor pressure measurement in biological and soil systems at high humidity.

Science 128:1084-1090. 
Rogers, W. S. 1935. A soil moisture meter depending on the capillary pull of the soil. J. Agr. Sci. 25:326-343.

Rose, C. W. 1966. Agricultural Physics. Robert Maxwe11, M.C., M.D. p. 132 .

Spanner, D. C. 1951. The peltier effect and its use in the measurement of suction pressure. J. Exp. Botany 2:145-168.

Stanhi11, G. 1957. The effect of difference in soil moisture status on plant growth. Soil Sci. 48:205-214.

Stocker, 0. 1930. Über die Messugn von Bodensaughkräften and ihren Verhältnis su den Wurzelsaugkräften. Z. Bot. 23:27-56.

Tanner, C. B., and R. J. Hanks. 1952. Moisture hysteresis in gypsum moisture blocks. Proc. Soil Sci. Soc. Amer. 16:48-51.

Taylor, S. A., D. D. Evans, and W. D. Kemper. 1961. Evaluation of soil water. Utah Agr. Exp. Station Bull. No. 426.

Thomas, M. D. 1921. Agneous vapor pressure of soils. Soil Sci. 11: 409-434.

Weaver, H. A., and Jamison, V. C. 1951. Limitation in the use of electrical resistances soil moisture units. Agron. J. 43:602-605.

Wiebe, H. H., G. S. Campbel1, W. H. Gardner, S. L. Rawlins, J. W. Cary, and R. W. Brown. 1971. Measurement of plant and soil water status. Utah Agr. Expt. Station Bull. 484.

Woodruff, C. M. 1941. Soil moisture and plant growth in relation to pH. Soil Sci. Amer. Proc. (1940) 5:36-41.

Zollinger, W. D., G. S. Campbe11, and S. A. Taylor. 1966. Comparison of water potential measurements made using two types of thermocouple psychrometers. Soil Sci. 102:231-239. 
APPENDIX 
Table 5. Calibration data from samples wetted to certain water content in a constant temperature chamber. $\psi$ was measured with the thermocouple psychrometer. Temperature of calibration was $15 \pm 0.1^{\circ} \mathrm{C} . \quad \mathrm{T}=$ uncertain contact. $\mathrm{B}=$ good contact

\begin{tabular}{|c|c|c|c|}
\hline$\theta$ of F. P. & W of soil $\psi$ in bars & $\begin{array}{c}M \text { and } M \\
\text { Reading in bars }\end{array}$ & $\begin{array}{l}\text { Temp. } \\
\text { in }{ }^{\circ} \mathrm{C}\end{array}$ \\
\hline $\bar{T}$ & Mesa & $\mathrm{T}$ & \\
\hline
\end{tabular}

Replication 1

$\begin{array}{lrrrrrr}25.67 & 25.48 & 5 \% & 20 & 22 & 25 & 15 \pm .1^{\circ} \mathrm{C} \\ 37.16 & 41.16 & 10 \% & 5 & 3.5 & 2 & \\ 41.71 & 89.92 & 15 \% & .25 & 1.7 & .095 & \end{array}$

Replication 2

$\begin{array}{lrrrrrr}25.20 & 24.73 & 5 \% & 20 & 25 & 25 & 15 \pm .1^{\circ} \mathrm{C} \\ 36.11 & 41.46 & 10 \% & 5 & 4 & 2 & \\ 43.26 & 93.54 & 15 \% & .25 & 1.5 & .085 & \end{array}$

Replication 3

\begin{tabular}{rrrrrrr}
25.70 & 23.35 & $5 \%$ & 21 & 22 & 30 & $15 \pm .1{ }^{\circ} \mathrm{C}$ \\
34.96 & 41.62 & $10 \%$ & 5 & 5 & 1.8 & \\
40.27 & 86.75 & $15 \%$ & .25 & 2.2 & .1 & \\
\hline
\end{tabular}

Mesa - subsoil

Replication 1

$\begin{array}{rrrrrrr}25.59 & 22.53 & 7 \% & 22 & 22 & 35 & 15 \pm .1^{\circ} \mathrm{C} \\ 33.27 & 29.25 & 10 \% & 11 & 7 & 13 & \\ 38.62 & 37.14 & 15 \% & 6 & 2.7 & 4 & \\ 47.12 & 68.91 & 20 \% & .5 & .6 & .18 & \end{array}$

Replication 2

$\begin{array}{rrrrrrr}23.97 & 21.56 & 7 \% & 23 & 32 & 42 & 15 \pm .1{ }^{\circ} \mathrm{C} \\ 32.18 & 28.45 & 10 \% & 11 & 8 & 16 & \\ 35.92 & 31.40 & 15 \% & 8 & 5 & 9 & \\ 45.13 & 69.23 & 20 \% & .5 & .9 & & .16 \\ & & & & & & \\ & & & & & & \\ 24.07 & 21.50 & 7 \% & 23 & 32 & 42 & 15 \pm .1{ }^{\circ} \mathrm{C} \\ 30.06 & 29.45 & 10 \% & 11 & 13 & 15 & \\ 34.75 & 33.28 & 15 \% & 7 & 5 & 7 & \\ 46.48 & 68.76 & 20 \% & .5 & .7 & .16 & \end{array}$


Table 5. Continued

\begin{tabular}{|c|c|c|c|}
\hline$\theta$ of F. P. & W of soil $\psi$ in bars & $\begin{array}{l}\mathrm{M} \text { and } \mathrm{M} \\
\text { Reading in bars }\end{array}$ & $\begin{array}{l}\text { Temp. } \\
\text { in }{ }^{\circ} \mathrm{C}\end{array}$ \\
\hline
\end{tabular}

Nibley

Replication 1

$\begin{array}{rrrrrrr}10.54 & 10.47 & 5 \% & & 300 & 300 & 15 \pm .1{ }^{\circ} \mathrm{C} \\ 28.19 & 25.11 & 10 \% & 18 & 17 & 25 & \\ 38.21 & 33.30 & 15 \% & 8 & 3 & 7 & \\ 45.08 & 45.59 & 20 \% & 3 & 1 & 8\end{array}$

Replication 2

\begin{tabular}{|c|c|c|c|c|c|c|}
\hline 9.98 & 9.67 & $5 \%$ & & 300 & 300 & $15 \pm .1^{\circ} \mathrm{C}$ \\
\hline 26.92 & 24.64 & $10 \%$ & 20 & 19 & 26 & \\
\hline 35.99 & 34.30 & $15 \%$ & 7.5 & 4 & 6 & \\
\hline 42.35 & 45.76 & $20 \%$ & 3 & 1.7 & .8 & \\
\hline \multicolumn{7}{|c|}{ Replication 3} \\
\hline 8.81 & 8.79 & $5 \%$ & & 400 & 400 & $15 \pm .1^{\circ} \mathrm{C}$ \\
\hline 26.33 & 23.79 & $10 \%$ & 20 & 22 & 31 & \\
\hline 35.29 & 32.60 & $15 \%$ & 8 & 5 & 8 & \\
\hline 42.93 & 47.83 & $20 \%$ & 2.5 & 1.5 & .6 & \\
\hline
\end{tabular}


Table 6. Same as Table 5 except temperature of calibration was $20 \pm$ $.1^{\circ} \mathrm{C}$.

\begin{tabular}{|c|c|c|c|}
\hline$\theta$ of F. P. & W of soil $\psi$ in bars & $\begin{array}{c}M \text { and } M \\
\text { Reading in bars }\end{array}$ & $\begin{array}{l}\text { Temp } \\
\text { in }{ }^{\circ} \mathrm{C}\end{array}$ \\
\hline
\end{tabular}

Mesa

Replication 1

$\begin{array}{llrcccc}25.63 & 23.53 & 5 \% & 21 & 22 & 32 & 20 \pm .1^{\circ} \mathrm{C} \\ 35.54 & 34.87 & 10 \% & 5 & 4.5 & 5 & \\ 38.29 & 70.87 & 15 \% & .33 & 3 & 0.16 & \end{array}$

Replication 2

$\begin{array}{lrrrccc}24.48 & 23.48 & 5 \% & 21 & 24 & 32 & 20 \pm .1^{\circ} \mathrm{C} \\ 33.84 & 35.04 & 10 \% & 5 & 6 & 5 & \\ 37.10 & 70.54 & 15 \% & .33 & 3.5 & 0.16 & \end{array}$

Replication 3

$\begin{array}{lrrrrrr}25.07 & 22.73 & 5 \% & 22 & 23 & 32 & 20 \pm .1^{\circ} \mathrm{C} \\ 34.77 & 35.20 & 10 \% & 5 & 5 & 5 & \\ 36.74 & 70.56 & 15 \% & .33 & 3.5 & 0.16 & \end{array}$

Mesa - subsoi1

Replication 1

$\begin{array}{lrrcccc}20.45 & 18.44 & 5 \% & 41 & 50 & 70 & 20 \pm .1{ }^{\circ} \mathrm{C} \\ 32.88 & 29.59 & 10 \% & 8 & 7 & 11 & \\ 40.21 & 38.75 & 15 \% & 3 & 2.2 & 2.5 & \\ 45.80 & 70.20 & 20 \% & .33 & .8 & -16 & \end{array}$

Replication 2

$\begin{array}{lrrrrrr}19.45 & 17.65 & 5 \% & 43 & 50 & 80 & 20 \pm .1{ }^{\circ} \mathrm{C} \\ 30.86 & 28.19 & 10 \% & 9 & 10 & 16 & \\ 39.20 & 36.29 & 15 \% & 3.5 & 2.5 & 4 & \\ 44.42 & 69.35 & 20 \% & .33 & .6 & .17 & \end{array}$

Replication 3

\begin{tabular}{rrrrrrr}
19.04 & 17.13 & $5 \%$ & 43 & 50 & 100 & $20 \pm .1{ }^{\circ} \mathrm{C}$ \\
30.77 & 28.28 & $10 \%$ & 9 & 10 & 16 & \\
37.65 & 35.59 & $15 \%$ & 3.9 & 3 & 4 \\
45.28 & 68.39 & $20 \%$ & .33 & .5 & .175 & \\
\hline
\end{tabular}


Table 6. Continued

\begin{tabular}{llll}
\hline & W of soil $\psi$ in bars & $\begin{array}{c}M \text { and } M \\
\text { Reading in bars }\end{array}$ & $\begin{array}{c}\text { Temp. } \\
\text { in }{ }^{\circ} \mathrm{C}\end{array}$ \\
\hline $\mathrm{T}$ & B & $\mathrm{T}$ & $\mathrm{B}$
\end{tabular}

Nibley

Replication 1

$\begin{array}{rrrrrrr}20.71 & 18.50 & 7 \% & 41 & 50 & 70 & 20 \pm .1^{\circ} \mathrm{C} \\ 29.18 & 26.44 & 10 \% & 15 & 14 & 20 & \\ 35.14 & 29.41 & 15 \% & 7.5 & 5 & 12 & \end{array}$

Replication 2

$\begin{array}{rrrrrrr}21.39 & 19.44 & 7 \% & 39 & 50 & 63 & 20 \pm .1^{\circ} \mathrm{C} \\ 28.80 & 26.49 & 10 \% & 15 & 14 & 20 & \\ 34.05 & 30.87 & 15 \% & 7 & 6 & 10 & \end{array}$

Replication 3

\begin{tabular}{rrrrrrr}
20.65 & 19.45 & $7 \%$ & 40 & 50 & 63 & $20 \pm .1^{\circ} \mathrm{C}$ \\
28.48 & 25.49 & $10 \%$ & 15 & 14 & 22 & \\
33.29 & 30.71 & $15 \%$ & 7 & 7 & 10 & \\
\hline
\end{tabular}


Table 7. Same as Table 5 except temperature of calibration was $24 \pm .1^{\circ} \mathrm{C}$

\begin{tabular}{llllll}
$\theta$ of F.P. & W of soil $\psi$ in bars & $\begin{array}{c}\text { M and } M \\
\text { Reading in bars }\end{array}$ & $\begin{array}{l}\text { Temp } \\
\text { in }{ }^{\circ} \mathrm{C}\end{array}$ \\
\hline T & B & T & $B$
\end{tabular}

\section{$\underline{\text { Mesa }}$}

Replication 1

$\begin{array}{rrrcrcr}29.95 & 31.22 & 5 \% & 15.5 & 12 & 10 & 24 \pm .1^{\circ} \mathrm{C} \\ 35.74 & 51.90 & 10 \% & 4 & 4 & 3 & \\ 39.30 & 107.01 & 15 \% & .28 & 2 & .06 & \end{array}$

Replication 2

$\begin{array}{rrrrrrr}28.84 & 29.75 & 5 \% & 15 & 15 & 12 & 24 \pm .1^{\circ} \mathrm{C} \\ 33.70 & 53.11 & 10 \% & 4 & 6 & .25 & \\ 35.90 & 105.00 & 15 \% & .29 & 4 & .07 & \end{array}$

Replication 3

\begin{tabular}{rrrrrrr}
28.49 & 29.39 & $5 \%$ & 15.5 & 15 & 12.5 & $24 \pm .1^{\circ} \mathrm{C}$ \\
33.70 & 50.63 & $10 \%$ & 4.4 & 6 & .4 & \\
37.13 & 106.04 & $15 \%$ & .28 & 3.5 & .065 & \\
\hline
\end{tabular}

Mesa - subsoil

Replication 1

$\begin{array}{lrrrrrr}20.44 & 19.60 & 5 \% & 41 & 60 & 60 & 24 \pm .1^{\circ} \mathrm{C} \\ 32.34 & 32.65 & 10 \% & 13 & 8 & 7 & \\ 40.34 & 44.41 & 15 \% & 5 & 2.2 & 1 \\ 45.44 & 73.68 & 20 \% & 1 & .9 & .15\end{array}$

Replication 2

$\begin{array}{rrrrrrr}19.90 & 18.40 & 5 \% & 45 & 60 & 80 & 24 \pm .1^{\circ} \mathrm{C} \\ 30.97 & 30.97 & 10 \% & 14 & 10 & 10 & \\ 36.18 & 44.43 & 15 \% & 5.3 & 4 & 1 & \\ 43.96 & 69.40 & 20 \% & 1.3 & 1 & .16 & \end{array}$

Replication 3

\begin{tabular}{rrrrrrr}
18.67 & 16.70 & $5 \%$ & 46 & 75 & 100 & $24 \pm .1^{\circ} \mathrm{C}$ \\
29.84 & 30.11 & $10 \%$ & 14 & 12 & 12 & \\
37.67 & 45.47 & $15 \%$ & 5.3 & 3 & 8 \\
45.37 & 72.04 & $20 \%$ & 1 & 1 & .16 & \\
\hline
\end{tabular}


Table 7. Continued

\begin{tabular}{|c|c|c|c|c|c|c|c|}
\hline$\theta$ of $F$. & P. & W of soil & $\Psi$ in bars & $\begin{array}{l}\mathrm{M} \text { an } \\
\text { Reading }\end{array}$ & $\begin{array}{l}\text { M } \\
\text { n bars }\end{array}$ & & $\begin{array}{l}\text { Temp. } \\
\text { in }{ }^{\circ} \mathrm{C}\end{array}$ \\
\hline \multicolumn{8}{|c|}{ Nibley } \\
\hline \multicolumn{8}{|c|}{ Replication 1} \\
\hline 17.24 & 16.39 & $5 \%$ & 50 & 100 & 110 & 24 & $\pm .1^{\circ} \mathrm{C}$ \\
\hline 32.09 & 33.08 & $10 \%$ & 11 & 8.7 & 7 & & \\
\hline 37.45 & 43.08 & $15 \%$ & 5 & 3.8 & 1.5 & & \\
\hline 46.66 & 67.94 & $20 \%$ & 1 & .7 & .17 & & \\
\hline 76.60 & 96.74 & $25 \%$ & .3 & .13 & .08 & & \\
\hline \multicolumn{8}{|c|}{ Replication 2} \\
\hline 15.77 & 16.13 & $5 \%$ & 50 & 110 & 110 & 24 & $\pm .1^{\circ} \mathrm{C}$ \\
\hline 29.52 & 30.03 & $10 \%$ & 12.5 & 12 & 12 & & \\
\hline 35.80 & 42.15 & $15 \%$ & 5 & 4 & 1.7 & & \\
\hline 42.32 & 63.66 & $20 \%$ & 1.5 & 1.7 & .18 & & \\
\hline 72.47 & 96.59 & $25 \%$ & 0.3 & .15 & .08 & & \\
\hline \multicolumn{8}{|c|}{ Replication 3} \\
\hline 14.90 & 14.54 & $5 \%$ & 60 & 130 & 130 & $24=$ & $\pm .1^{\circ} \mathrm{C}$ \\
\hline 29.15 & 27.70 & $10 \%$ & 14 & 13 & 16 & & \\
\hline 35.30 & 40.70 & $15 \%$ & 6 & 5 & 2 & & \\
\hline 40.95 & 60.93 & $20 \%$ & 2 & 1.8 & .19 & & \\
\hline 69.90 & 92.50 & $25 \%$ & .33 & .16 & .09 & & \\
\hline
\end{tabular}


Table 8. Same as Table 5 except temperature of calibration without control

\begin{tabular}{|c|c|c|c|}
\hline$\theta$ of F. P. & $\underline{W}$ of soil $\psi$ in bars & $\begin{array}{l}\mathrm{M} \text { and } \mathrm{M} \\
\text { Reading in bars }\end{array}$ & Temp. \\
\hline B & & B & \\
\hline
\end{tabular}

Replication 1

$\begin{array}{lrrrcrl}25.58 & 25.13 & 5 \% & 27 & 20 & 24 & \text { No temp. } \\ 36.16 & 44.25 & 10 \% & 4 & 4 & 1.2 & \text { control } \\ 16.35 & 89.21 & 15 \% & .33 & .8 & 0.1 & \end{array}$

Replication 2

$\begin{array}{lrrrrrr}24.98 & 24.98 & 5 \% & 27 & 30 & 30 & \text { No temp. } \\ 36.00 & 43.36 & 10 \% & 4 & 4 & 1.4 & \text { control } \\ 41.69 & 89.22 & 15 \% & .33 & 2 & 0.1 & \end{array}$

Replication 3

\begin{tabular}{lrrrrrr}
24.81 & 24.62 & $5 \%$ & 27 & 30 & 30 & No temp. \\
34.53 & 43.40 & $10 \%$ & 4 & 5 & 1.4 & contro1 \\
41.46 & 86.27 & $15 \%$ & .33 & 2 & 0.12 & \\
\hline
\end{tabular}

\section{Desert soil}

Replication 1

$\begin{array}{rrrrrrr}22.48 & 23.26 & 10 \% & 40 & 40 & 35 & \text { No temp. } \\ 25.97 & 30.56 & 15 \% & 28 & 20 & 10 & \text { control } \\ 29.92 & 38.76 & 20 \% & 9 & 12 & 2.8 & \\ 34.15 & 54.36 & 25 \% & 4 & 6 & 0.2 & \end{array}$

Replication 2

$\begin{array}{rrrrrrr}22.70 & 22.62 & 10 \% & 40 & 40 & 36 & \text { No temp. } \\ 25.47 & 28.44 & 15 \% & 28 & 25 & 16 & \text { control } \\ 29.67 & 37.79 & 20 \% & 9 & 12 & 3 & \\ 33.59 & 53.17 & 25 \% & 4 & 6 & 0.25 & \end{array}$

Replication 3

\begin{tabular}{lllllll}
21.64 & 21.97 & $10 \%$ & 40 & 40 & 40 & No temp. \\
28.71 & 27.38 & $15 \%$ & 18 & 14 & 18 & contro1 \\
29.59 & 36.67 & $20 \%$ & 8.5 & 12 & 3.5 & \\
33.27 & 51.44 & $25 \%$ & 4 & 7 & 0.35 & \\
\hline
\end{tabular}


Table 8. Continued

\begin{tabular}{lllll}
$\theta$ of F. P. & W of soil $\psi$ in bars & $\begin{array}{c}M \text { and } M \\
\text { Reading in bars }\end{array}$ & Temp. \\
\hline B & Nibley & &
\end{tabular}

Replication 1

$\begin{array}{rrrrrrr}24.79 & 22.13 & 7 \% & 27 & 29 & 40 & \text { No temp. } \\ 30.92 & 29.00 & 10 \% & 9.5 & 10 & 14 & \text { contro1 } \\ 39.80 & 39.80 & 15 \% & 3.5 & 2 & 2 & \end{array}$

Replication 2

$\begin{array}{rrrrrrr}23.80 & 22.50 & 7 \% & 30 & 30 & 40 & \text { No temp. } \\ 29.73 & 28.13 & 10 \% & 10 & 13 & 16 & \text { contro1 } \\ 38.76 & 37.67 & 15 \% & 3.5 & 2.5 & 3 & \\ & & & \text { Replication } 3 & & \\ 23.02 & 21.34 & 7 \% & 32 & 35 & 50 & \text { No temp. } \\ 30.27 & 29.00 & 10 \% & 10 & 13 & 14 & \text { contro1 } \\ 37.90 & 37.78 & 15 \% & 3.5 & 3 & 3 & \end{array}$


Table 9. Same as Table 5 except temperature of calibration was $32^{\circ} \mathrm{C}$

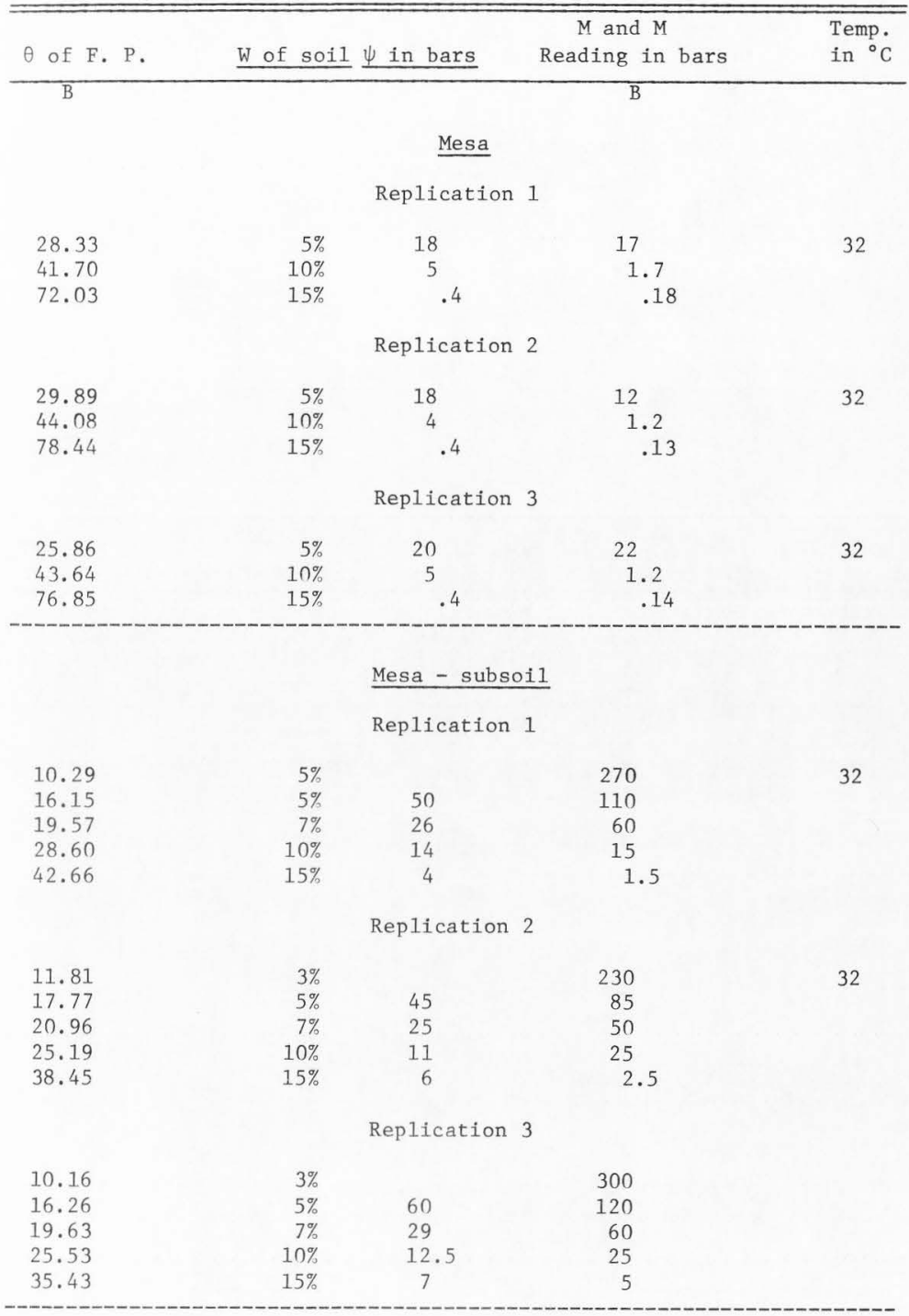


Table 9. Continued

\begin{tabular}{|c|c|c|c|c|}
\hline$\theta$ of F. P. & W of soil & $\psi$ in bars & $\begin{array}{l}M \text { and } M \\
\text { Reading in bars }\end{array}$ & $\begin{array}{l}\text { Temp. } \\
\text { in }{ }^{\circ} \mathrm{C}\end{array}$ \\
\hline B & & & B & \\
\hline \multicolumn{5}{|c|}{ Nibley } \\
\hline \multicolumn{5}{|c|}{ Replication 1} \\
\hline 11.82 & $3 \%$ & & 220 & 32 \\
\hline 16.03 & $5 \%$ & 41 & 120 & \\
\hline 22.28 & $7 \%$ & 20 & 40 & \\
\hline 32.31 & $10 \%$ & 9 & 9 & \\
\hline \multicolumn{5}{|c|}{ Replication 2} \\
\hline 12.32 & $3 \%$ & & 190 & 32 \\
\hline 16.75 & $5 \%$ & 38 & 100 & \\
\hline 27.28 & $7 \%$ & 18 & 18 & \\
\hline 35.71 & $10 \%$ & 8.6 & 4 & \\
\hline 47.77 & $15 \%$ & 4 & .55 & \\
\hline \multicolumn{5}{|c|}{ Replication 3} \\
\hline 13.77 & $3 \%$ & & 170 & 32 \\
\hline 16.43 & $5 \%$ & 38 & 110 & \\
\hline 24.40 & $7 \%$ & 19 & 30 & \\
\hline 26.91 & $10 \%$ & 14 & 20 & \\
\hline 42.32 & $15 \%$ & 4 & 1.5 & \\
\hline
\end{tabular}


Table 10. Data were collected from soil samples obtained at known heights above the water table, the filter papers were equilibrated the same as in Table 5 .

\begin{tabular}{|c|c|c|c|c|c|}
\hline $\begin{array}{ll}\theta & 0\end{array}$ & F. P. & $\psi$ in bars & $\begin{array}{l}\text { Height } \\
\text { in } \mathrm{cm}\end{array}$ & \multicolumn{2}{|c|}{$\begin{array}{l}M \text { and } M \\
\text { Reading }\end{array}$} \\
\hline$\overline{\text { Good }}$ & Uncertain & & & Good & Uncertain \\
\hline 167.00 & 165.35 & 0.034 & 35 & 0.015 & 0.016 \\
\hline 174.41 & 173.32 & 0.0311 & 30.7 & 0.013 & 0.013 \\
\hline 178.16 & 176.45 & 0.029 & 30.0 & 0.012 & 0.0125 \\
\hline 191.55 & 188.87 & 0.024 & 24.5 & 0.0085 & 0.009 \\
\hline 206.55 & 203.63 & 0.017 & 17.0 & 0.006 & 0.0065 \\
\hline 218.99 & 220.13 & 0.010 & 10.0 & 0.0045 & 0.0045 \\
\hline 163.12 & 160.22 & 0.032 & 33.0 & 0.016 & 0.018 \\
\hline 169.13 & 168.19 & 0.028 & 29.0 & 0.014 & 0.015 \\
\hline 182.00 & 180.33 & 0.022 & 22.5 & 0.011 & 0.012 \\
\hline 201.34 & 203.45 & 0.018 & 18.5 & 0.007 & 0.006 \\
\hline 224.38 & 222.39 & 0.0126 & 13.00 & 0.004 & 0.004 \\
\hline
\end{tabular}


Table 11. Same as Table 5 except temperature of calibration was $24 \pm .1^{\circ} \mathrm{C}$ and the filter paper separated from the soil by a cylinder

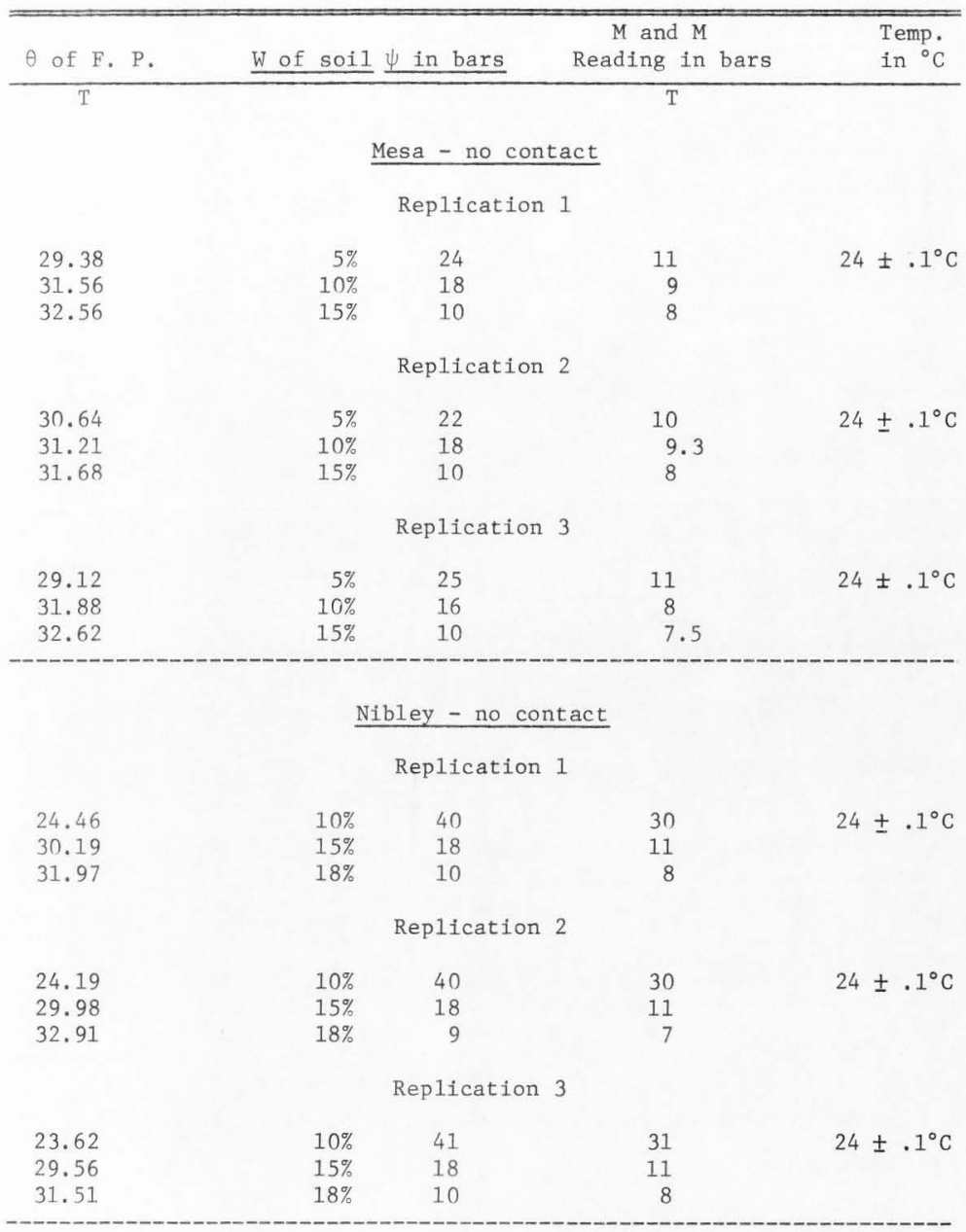


Table 11. Continued

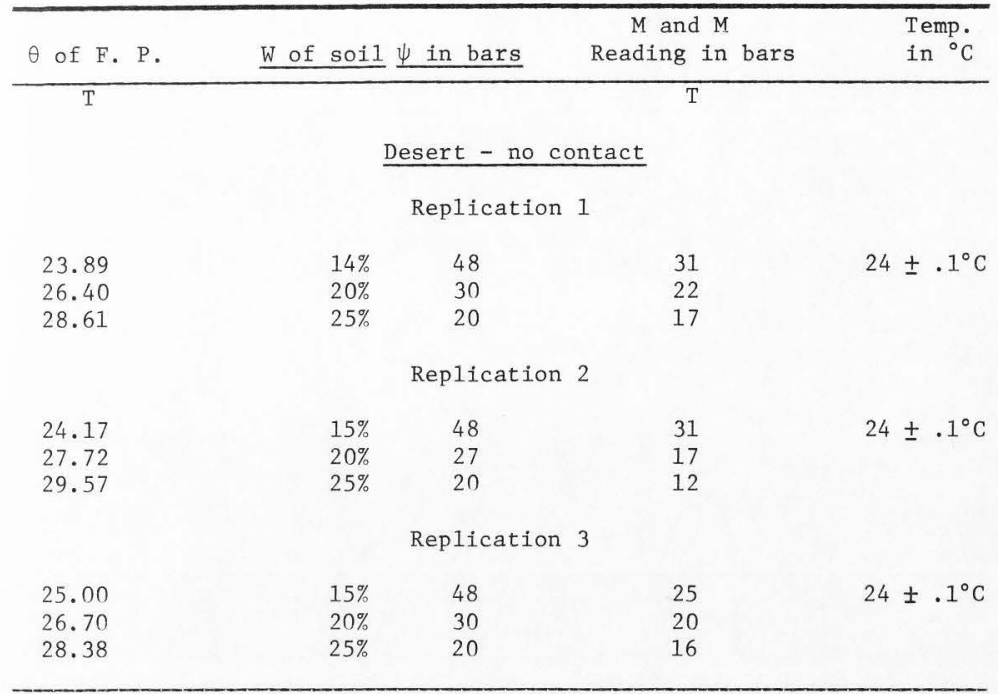


Table 12. Calibration data of the filter paper exposed to saturated salts in constant temperature chamber

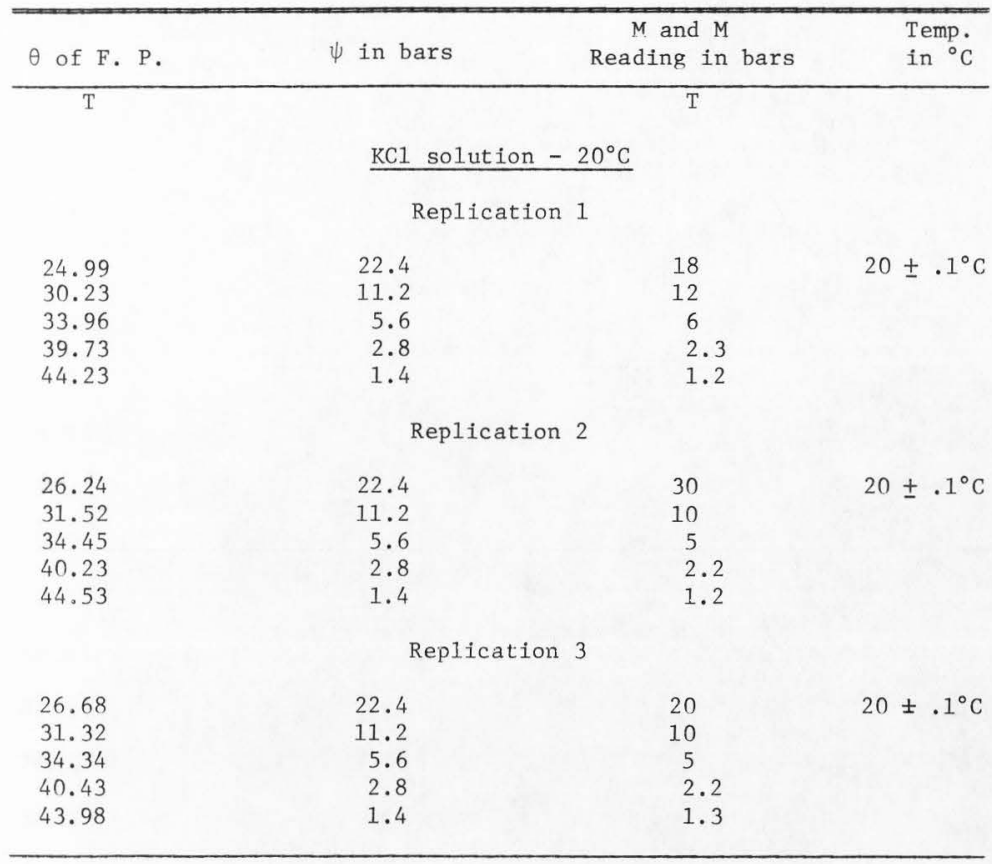


Table 13. Same as Table 5 except temperature of calibration was $20 \pm 1^{\circ} \mathrm{C}$ and $\psi$ was measured using the pressure plate membrane

\begin{tabular}{|c|c|c|c|c|c|}
\hline \multicolumn{2}{|c|}{$\theta$ of F. P. } & \multirow{2}{*}{${ }_{\text {in }}^{\psi}$ bars } & \multicolumn{2}{|c|}{$\begin{array}{c}M \text { and } M \\
\text { Reading in bars }\end{array}$} & \multirow{2}{*}{$\begin{array}{l}\text { Temp. } \\
\text { in }{ }^{\circ} \mathrm{C}\end{array}$} \\
\hline Good & Uncertain & & Good & Uncertain & \\
\hline 62.35 & 48.13 & 1 & 0.18 & 0.6 & $20 \pm 1^{\circ} \mathrm{C}$ \\
\hline 63.75 & 53.26 & 1 & 0.17 & 0.25 & \\
\hline 62.32 & 45.18 & 1.2 & 0.18 & 1.0 & \\
\hline 68.03 & 60.35 & .5 & 0.16 & 0.2 & \\
\hline 73.09 & 63.18 & .5 & 0.14 & .18 & \\
\hline 70.39 & 59.24 & .56 & 0.15 & 0.2 & \\
\hline 72.17 & 58.88 & .33 & 0.15 & 0.2 & \\
\hline 76.27 & 59.63 & .33 & 0.13 & 0.2 & \\
\hline 82.35 & 61.23 & .33 & 0.12 & 0.19 & \\
\hline 76.02 & 60.95 & .30 & 0.13 & 0.2 & \\
\hline 30.32 & 31.98 & 17 & 12.0 & 8.5 & \\
\hline 32.13 & 25.45 & 15.5 & 8.5 & 25 & \\
\hline 32.09 & 31.86 & 14 & 8.5 & 8.5 & \\
\hline 29.28 & 32.27 & 14 & 14 & 8.5 & \\
\hline
\end{tabular}


VITA

Sameir A1-Khafaf

Candidate for the Degree of

Master of Science

Thesis: Evaluation of the Filter Paper Method for Estimating Soil Water Potential

Major Field: Soil Physics

Biographical Information:

Personal Data: Born at Nenava, Iraq, March 14, 1949, son of Khalil Al-Khafaf and Hessa Rashaan.

Education: Attended elementary school in Nenava, Iraq; attended secondary and high school in Nenava, Iraq; received the B.Sc. in Agriculture from the University of Mosul, Mosul, Iraq, June 1970; completed requirements for the Master of Science degree at Utah State University, April 1972. 